1 This manuscript has been accepted for publication at the Journal of Hydrology. The final published 2 version can be viewed at: https://doi.org/10.1016/j.jhydrol.2020.125821. 


\section{Saturation excess overland flow accelerates the spread of a}

${ }_{6}{ }^{a}$ Department of Civil and Environmental Engineering, University of California, Berkeley, Berkeley, CA, $7 \quad 94720$

${ }_{8}^{b}$ Centro de Investigaciones Científicas y Tecnológicas de Extremadura, Mérida, Badajoz 06800, Spain

$9^{c}$ Departamento de Física Aplicada, Centro Universitario de Mérida and Instituto de Computación

${ }_{10}$ Científica Avanzada (ICCAEx), Universidad de Extremadura, Badajoz 06800, Mérida, Spain

${ }_{11}^{d}$ Department of Civil, Environmental, and Mining Engineering, University of Western Australia, Perth,

12 Western Australia 6009 Australia

${ }_{13} *$ Corresponding author: jvwilkening@berkeley.edu

\section{${ }_{14}$ Abstract}

Plant pathogens are a major agent of disturbance in ecosystems worldwide. Disturbance by diseases which inhibit plant water uptake can alter the hydrological function of affected ecosystems. However, many plant pathogens are also sensitive to soil moisture and can be propagated by the transport of infectious tissue or reproductive structures in surface flow, so that hydrological processes can drive pathogen infection. These feed-forward and feed-back processes set up the possibility of complex ecohydrological dynamics relating plant disease and the water cycle. Here the generalist root pathogen Phytophthora cinnamomi $(\mathrm{Pc})$ is used as a case study to examine the potential importance of hydrological dynamics on disease spread. A numerical model of Pc growth and dispersal is used to investigate the importance of Pc transport in intermittent surface runoff compared to more continuous rhizosphere Pc spread via diffusion-like hyphal growth. We apply and test this model at two well-studied sites of Pc infection with contrasting hydrology: a Banksia woodland in Western Australia where deep sandy soils inhibit surface runoff, and an Erica heathland in the Spanish Central Plateau where relatively shallow soils on steep slopes generate intermittent saturation excess overland flow. Predictions of Pc spatial spread at the Spanish site improve when Pc transport in runoff is incorporated into the model, while no such improvements arise at the Australian site. Omitting transport in overland flow from model predictions at the Spanish site results in an average under-prediction of final pathogen patch areas by $350 \mathrm{~m}^{2}$ for 
each year of growth between observations, highlighting the importance of surface hydrological transport to Pc growth and spread and need for further studies. Hydrological theories that predict the occurrence of overland flow based on soil, topographic, and climate properties can be used to better incorporate this transport pathway and the influence of local hydrological processes in existing Pc risk assessment methods.

Keywords:Phytophthora cinnamomi, plant pathogens, overland runoff, spatial model

\section{Introduction}

Plant pathogens can affect forest composition, structure, and function, but the dynamics of these disturbances are generally less well understood than those due to abiotic disturbances (Flower \& GonzalezMeler, 2015). Vegetation infection and mortality caused by pathogens can alter forest water balance (Batini et al., 1980; Schofield et al., 1989, e.g.), and there are also potential feed-forward mechanisms by which hydrology can directly impact pathogens. For example, the growth and spread rates of many soil pathogens vary with water potential (Boyer, 1995; Colhoun, 1973; Cook \& Papendick, 1972; Crist \& Schoeneweiss, 1975; Desprez-Loustau et al., 2006; Dickenson \& Wheeler, 1981; Ferrin \& Stanghellini, 2006; Madar et al., 1989; Malajczuk \& Theodorou, 1979; Schober \& Zadoks, 1999; Suleman et al., 2001). This means that pathogen infection can influence and also be influenced by root zone water dynamics. The potential for pathogen propagules and infectious material to be transported by surface flow adds scope for further complex hydrological - pathogen feedback processes. In previous work, relationships between soil water potential and pathogen dynamics were used to relate regional hydroclimatic variations to pathogen risk (Thompson et al., 2013, 2014). The influence of hydrological transport processes on more localized pathogen spread, however, remains largely unexplored. Better understanding of this feedforward relationship between hydrology and disease disturbance is necessary for understanding coupled forest - pathogen - water systems and the implications for disturbance and ecosystem function.

In this study, we consider the soil-borne pathogen Phytophthora cinnamomi (Pc) as a case study to explore the importance of hydrological transport for disease spread. Pc is one of the world's most destructive plant pathogens (Burgess et al., 2017), posing a global threat to natural and agricultural systems (Lowe et al., 2000) that is expected to worsen as climates warm (Bergot et al., 2004; Chakraborty et al., 2000; Thompson et al., 2014). Pc forms necrotic lesions on roots and stems of infected host plants. Severe infection results in the loss of the majority of the fine root system in susceptible plants, inhibiting water uptake and causing mortality. Pc is a generalist pathogen affecting a huge array of plant species. For example, in south-west Western Australia, some 40\% of the more than 5000 endemic plant species are susceptible to Pc (Shearer et al., 2004). In Europe, Pc is decimating oak woodlands of Quercus ilex and Quercus suber (Brasier, 1996) and the chestnut forests (Vettraino et al., 2005). Pc 
is persistent in the environment and spreads rapidly through infected soil and water. Within the soil, it can spread via mycelial growth and root-root contact, and through the production of oospores, or motile zoocytes (Hardham \& Blackman, 2018). Under unfavorable conditions such as drought, Pc forms resilient chlamydospores that can persist and remain viable for months to years (Hwang \& Ko, 1978; Jung et al., 2013). Long-distance spread occurs through the mobilization of infected roots, soil, or fungal propagules by natural and anthropogenic processes (Ristaino \& Gumpertz, 2000).

In natural ecosystems, management strategies to address Pc infection involve prioritizing areas for quarantine, monitoring, and treatment. A component of this prioritization involves making assessments about the likely pathways and rates of Pc establishment and spread in a given landscape (e.g. Commonwealth of Australia, 2014; National Heritage Trust and Environment Australia, 2001). The growth dynamics of Pc are strongly coupled to environmental conditions (Thompson et al., 2013). Mycelial growth is inhibited under low water potentials (i.e. dry soil), declines with falling temperatures (Malajczuk \& Theodorou, 1979), and the pathogen is killed by protracted sub-freezing conditions (Marçais et al., 1996). In previous work, we used these environmental dependencies to predict the likelihood of Pc infection across soil type and climate conditions under steady state conditions using a parsimonious coupled soil moisture - pathogen growth model (Thompson et al., 2013, 2014). Here, we extend the modeling framework to consider the spatial spread of Pc infection, in particular considering whether observed patterns of disease spread are consistent with the pathogen being spread in overland flow. Because this potential transport mechanism has not been studied to date, we adopt an exploratory modeling approach to test the hypothesis that pathogen transport via overland flow is required to explain observations of disease spread. We compare this to a null hypothesis that spread is primarily attributable to non-hydrologic transport processes such as hyphal growth or root-root contact between infected and healthy plants within the soil.

For this purpose, we model multiple potential transport pathways that could contribute to Pc spread around disease foci. Mycelial root pathogens, including Pc, spread locally via growth along the host root system, a process that is well-represented via diffusion in soil pathogen models (Cunniffe \& Gilligan, 2008; Park et al., 2001). Pc also spreads locally due to zoocyte motility. In practice, the maximum observed scales of zoocyte movement and of mycelial extension are comparable, on the order of millimeters per day (Benjamin \& Newhook, 1982; Malajczuk \& Theodorou, 1979). Since observations of disease patches are typically coarse in space and time (e.g. observed on monthly timescales or longer, and on spatial scales of one to tens of meters) (Cardillo et al., 2018; Dawson \& Weste, 1985; Wilson et al., 2012), it is unlikely that the relative contribution of motile zoocytes versus mycelial expansion to this local growth can be determined from observations of Pc disease, and thus will be considered jointly represented by the "diffusive" spread. However, natural (rather than anthropogenic) transport of Pc may not be limited to the rhizosphere. Observations of Pc spread persistently reveal features - such as faster downslope 
than upslope spread, or spatial associations between Pc infection and surface flow channels - which are consistent with Pc transport in surface flow (see Table 1 for details). Although repeated recovery of Pc material in surface flow, subsurface flows, and drainage waters (Kinal et al., 1993; Kliejunas \& Ko, 1976; Reeser et al., 2011; Thomson \& Allen, 1974) supports the feasibility of hydrological transport, its importance in setting the direction and speed of disease spread is not well understood. Pc will not grow in permanently saturated conditions (Malajczuk \& Theodorou, 1979). Yet the occurrence of surface flow in areas that are not perennially saturated is usually intermittent, generated by infiltration excess runoff during intense storms (Horton, 1933), or by saturation excess runoff following transient saturation of the soil (Dunne \& Black, 1970).

Although the intermittent nature of surface runoff might suggest it is unimportant for Pc spread, water could readily transport Pc over tens to hundreds of meters, suggesting that its role should be explored. In this work, we aim to investigate the potential for Pc transport in overland flow to have contributed to observed patterns of $\mathrm{Pc}$ disease. The modeling approach invoked draws on the simple $\mathrm{Pc}$ growth model presented in Thompson et al. $(2013,2014)$ and couples it to equivalently simple representations of water balance in the soil column, surface routing, and Pc transport. We note upfront that, to date, no mechanistic studies have been undertaken to reveal the details of such transport, and no field studies are available that simultaneously measure hydrological processes and Pc disease spread. For this reason, the modeling treatment used is simple and represents only the hydrological processes relevant to the two case study sites considered. This approach is common in exploratory modeling for the purposes of first-order hypothesis testing, and is distinct from predictive modeling approaches that aim to make quantitative forecasts, and require extensive calibration, validation and uncertainty analysis in order to do so (Harmel et al., 2014; Larsen et al., 2016; Larsen et al., 2014; Rastetter, 2017). The primary aim of the modeling exercise is to verify the consistency of hypothesized Pc transport in overland flow with observed disease spread patterns in space, as a spur to better informing management practices and highlighting future research needs.

To extend the Pc growth model presented in Thompson et al. (2013, 2014), we include diffusionlike local spread and passive transport of Pc infectious material in surface water overland flow. The model is calibrated and tested against spatiotemporally resolved observations of disease spread at two contrasting sites in Western Australia and Spain. The site in Western Australia shows evidence of minimal surface runoff and the site in Spain shows strong evidence of saturation excess runoff, such that modeling studies of the two sites have the potential to investigate the role of overland flow in pathogen transport at the latter, with the former acting as a sort of control. The spatial spread of Pc infection at these sites display quite different spatial patterns (Figure 1) which we hypothesize arise from their distinct hydrological behavior. Typical of Pc monitoring locations, however, no detailed hydrological observations are available. We calibrate the model twice at each site, once including overland flow as a 
Pc transport mechanism (termed Overland Transport Case) and once omitting this mechanism (termed "Diffusion" Optimized Case), and compare the model predictions and performance in each case. While direct validation of the model results is not possible because of the aforementioned data limitations, checks for reasonable model behavior and possible errors are done both by comparing the modeled soil moisture distributions to data from similar sites and by comparing values of calibrated parameters which describe behaviors that are expected to be consistent across sites. From the model output for the two calibration cases, the degradation in model performance when overland flow is omitted provides a metric of whether including overland flow is necessary to describe observed patterns of disease spread. The models calibrated using overland flow are then run in a third case where the calibration is retained, but the overland flow process is turned off (termed Overland Off Case)- providing a measure of the disease spread predicted without transport in overland flow. The reduced extent of disease spread when overland flow transport is suppressed provides a measure of the importance of disease spread due to surface runoff at each site. We then interpret the model findings in the context of what they tell us about the interactions between pathogens and hydrology, including the implications for management practices and directions for future study.

\section{Model}

The mean-field spatial dynamics of soil-borne pathogens can be modeled with reaction-diffusion type equations (Cunniffe \& Gilligan, 2008; Park et al., 2001), specifying the growth rate of pathogen biomass at a point, and its diffusivity (Andow et al., 1990; Okubo \& Levin, 2013). The strong dependence of Pc mycelial growth and survival on soil moisture and temperature means that both growth and diffusion terms in the spread model are functions of local environmental conditions. The soil environmental conditions must therefore also be modeled or prescribed based on climate observations and local soil properties.

To add transport via overland flow to this model involves specifying runoff production rates, a routing model to define the direction of flow, and a representation of mobilization, mixing, and deposition of propagules in the surface water flow. The model thus has three components: a soil water balance model (detailed in Section 2.1), a runoff routing and propagule transport model (detailed in Section 2.2), and the pathogen growth and spread model (detailed in Section 2.3). The model is implemented on a twodimensional square grid, where cells take dimensions of $\Delta x$ and $\Delta y$. Table 2 summarizes all the variables and parameters of the model components, and a schematic showing the relation between components is shown in Figure 2.

The hydrological model formulation was deliberately tailored to the hydrologic characteristics of the case study sites. The Western Australian case study site is situated on deep sands with saturated 
hydraulic conductivity reported as $3.7 \mathrm{~m} /$ day (Salama et al., 2005). Examination of the local intensityfrequency-duration curves (Australian Bureau of Meteorology, 2016) shows that there is a less than 1\% probability that even short storms generate rainfall at intensities in excess of this value, suggesting that there is no scope for infiltration excess overland flow at this site. Similarly, the Spanish case study site is situated on shallow, weathered mineral soils with very high reported hydraulic conductivities of nearly $4.5 \mathrm{~cm} /$ minute (Gómez-Paccard et al., 2015). Although local intensity-frequency-duration curves are not available, generating infiltration excess runoff on these soils would require that the highest daily rainfall totals measured at the site arrive in storms of $<2$ minutes duration. This, coupled with the visually obvious surface erosion at the site, gives us confidence to focus on saturation excess as the main runoff generation mechanism, and to tailor the model development accordingly. The model does not include transport in subsurface water flows: subsurface lateral flow is negligible above the water table at the Western Australian site (Salama et al., 2005; Xu et al., 2003), and while the saturated hydraulic conductivity of the soils at the Spanish site is reasonably high, the soil moisture content of the soils is generally low (see Results Section), limiting lateral transport in unsaturated soils. In general, however, such subsurface transport is feasible and should be considered in sites where significant lateral subsurface flows occur (Kinal et al., 1993; Shea et al., 1983). We omit interception losses due to the sparse canopies at each site, and did not parameterize surface detention storage due to the steep topography in the Spanish case study location.

One advantage of using a minimal level of complexity in the hydrological model is that doing so maintains a comparable level of model complexity in the hydrological and disease spread components of the model, with the latter being limited by the current mechanistic understanding of the hypothesized processes. It also avoids adding additional calibration that would otherwise be needed, given the limited data available at the study sites. Coupling minimal complexity models ensures that the study focuses on the emergent behavior arising from the interaction of the model components. This is similar to approaches successfully used in comparable coupled hydrological models (e.g. in studying spatial dynamics of vegetation (Marani et al., 2006; Rietkerk et al., 2002; Van Wijk \& Rodriguez-Iturbe, 2002) and the probabilistic characteristics of soil moisture (Botter et al., 2008; Guswa et al., 2002; Milly, 1994; Porporato et al., 2004)). Adapting the model to sites with distinct hydrology (e.g. sites dominated by infiltration excess overland flow, with dense canopies, or less extreme terrain), would require only modest and relatively straightforward extensions of the current formulation.

\subsection{Soil water balance}

Soil water is represented with a mass balance model (Figure 2A) within a homogeneous vertical domain $z_{r}[\mathrm{~mm}]$, taken here as either the depth of the host plants' root zone or the depth to an impermeable soil layer, whichever is smaller. The mean relative soil water content $s[-]$ in this zone is given by 
$s=V_{\text {water }} /\left(n z_{r}\right)$, where $V_{\text {water }}$ is the volume of water per unit area $[\mathrm{mm}]$ and $n$ is the porosity of the soil [-]. The mass balance for the soil moisture is given by:

$$
\frac{\partial s}{\partial t}=\frac{f\left(P(t), s(t), K_{\text {sat }}\right)-g\left(E T_{\max }(t), s(t)\right)-L\left(s(t), K_{\text {sat }}\right)}{n \times z_{r}}
$$

where $f()$ represents the rate of infiltration, $g()$ the rate of evapotranspiration, and $L()$ the rate of percolation at the bottom boundary. This mass balance is implemented independently for each spatial location. Lateral transport of water in the soil is assumed negligible.

The rate of infiltration is defined as a function of the rainfall rate $P[\mathrm{~mm} /$ day $]$, the soil moisture, and the soil infiltration capacity, which we approximate with its saturated hydraulic conductivity $K_{\text {sat }}$ $[\mathrm{mm} /$ day $]$, as follows:

$$
f\left(P(t), s(t), K_{\text {sat }}\right)= \begin{cases}P & P<K_{\text {sat }} \text { and } s<1 \\ K_{\text {sat }} & P \geq K_{\text {sat }} \text { and } s<1 \\ L & s=1\end{cases}
$$

Approximating infiltration capacity with the saturated hydraulic conductivity could underestimate infiltration rates in unsaturated soils. This is unlikely to be problematic in the case study locations considering the high values of $K_{\text {sat }}$. Replacing the constant $K_{\text {sat }}$ assumption with a time varying infiltration model (Green-Ampt, Philips or similar) would be important in sites where infiltration excess overland flow occurs (Green \& Ampt, 1911; Philip, 1957).

Soil moisture losses due to evapotranspiration are described by a piece-wise function of soil moisture, following the approach of Porporato et al. (2004):

$$
g(s)= \begin{cases}0 & s \leq s_{w p} \\ E T_{\max } \frac{s-s_{w p}}{s^{*}-s_{w p}} & s_{w p}<s<s^{*} \\ E T_{\max } & s^{*} \leq s\end{cases}
$$

where $s_{w p}$ is the soil moisture wilting point (i.e. plants stop transpiring), and $s^{*}$ is the point of complete stomatal opening. Equation 3 states that evaporative losses are negligible below the wilting point, linearly increase with increasing soil moisture between the wilting point and the point of complete stomatal opening, and proceed at a maximum rate $E T_{\max }$ in wetter soils. We make the additional simplifications of: (i) prescribing $s_{w p}, s^{*}$, and $n$ as a function of soil type, (ii) estimating $E T_{\max }$ from weather data (see Section 3.1), and (iii) neglecting any possible relationship between Pc infection, plant health, and evaporation dynamics. Percolation [mm/day] at the bottom boundary to deeper soils follows Porporato et al. (2004): 


$$
L\left(s(t), K_{\text {sat }}\right)=K_{\text {sat }} s^{2 b+3}
$$

where $b[-]$ is the exponent of the soil-water retention curve for the corresponding soil type from Clapp and Hornberger (1978). For cases where the bottom boundary of the modeled soil domain is impervious, the percolation term is set to zero.

The water balance connects to the other two model components via the value of the soil moisture $s$, which is used as input to the pathogen biomass growth model (see Section 2.3 and Figure 2C), and by the production of saturation excess overland flow $q=P-f[\mathrm{~mm} /$ day $]$, when saturated soils have insufficient available storage for incoming precipitation. In situations where interception losses or surface detention storage are significant, additional loss terms could readily be introduced in the expression for $q$ (e.g. Gamage et al. (2015)), but are omitted for application to the case study sites. The runoff model (Figure 2B and Figure 3), described in more detail in Section 2.2, operates on the storm-averaged rate of flow production, $\left(q_{\text {storm }}, \mathrm{mm}_{\text {day }}{ }^{-1}\right)$ :

$$
q_{\text {storm }}=\frac{\sum_{t=0}^{t=t_{\text {storm }}} q(t) \Delta t}{t_{\text {storm }}}
$$

where $t_{\text {storm }}$ [day] is the length of the storm event and $\Delta t$ is the time step resolution of the model [day]. The duration of a storm event is considered to be the cumulative time of consecutive non-zero precipitation records, up to a maximum of 24 hours, after which it is treated as two discrete events.

\subsection{Surface flow routing and propagule transport}

This component of the model is new to this study, and therefore explained in detail below. Figure 3 outlines several of the key components of the transport model.

\subsubsection{Surface flow routing}

Storm averaged runoff $\left(q_{\text {storm }}\right)$ is routed along the land surface using the D- $\infty$ method (Tarboton, 1997) which specifies the fraction $\left(\phi_{i, j}\right)$ of flow in any upslope location (indexed as $i$ ) that passes through any specified downslope cell (indexed as $j$ ) (see Figure 3A). We approximate the dynamic processes of runoff production, routing, and their variation throughout a storm with a single, storm-averaged rate of flow production, and steady conditions assumed for runoff depths $(h)$, bulk velocity $(u)$, and transport properties. With these assumptions, $\phi_{i, j}$ and the average rate of runoff production $\left(q_{\text {storm }}\right)$ fully specify the runoff routing. For the case studies considered here, where flow is produced only on saturated soils, we assume that all grid cells are saturated, preventing any downslope infiltration of runoff. Such runoffrunon mechanisms, however, are often important in urban, dryland, and agricultural areas (McLaughlin et al., 2017; Thompson et al., 2010), and would require re-specification and derivation of the routing and 
pathogen transport solutions developed here.

\subsubsection{Pathogen transport}

We model the transport of Pc in the flow using a simple advection equation following the mean water flow path. The flow path is not necessarily aligned with the topographic grid, and has its own coordinate, $\ell[\mathrm{m}]$ (Figure 2B). For flow along this path, the concentration of pathogen biomass $\left(C,\left[\mathrm{~g} \mathrm{~m}^{-3}\right]\right)$ evolves as:

$$
\frac{\partial(h C)}{\partial t}=-\frac{\partial q_{c} C}{\partial \ell}+h(\text { Source }- \text { Sink })
$$

where $q_{c}$ is the water flux per unit width of the flowpath $\left[\mathrm{m}^{2}\right.$ day $\left.{ }^{-1}\right]$, and Source and Sink denote the rates of concentration increase due to Pc biomass being introduced to the flow from soil beneath the flowpath, and decrease due to its deposition. We assume that deposition follows first order linear kinetics, such that $\operatorname{Sink}(\ell, t)=\beta C(\ell, t)$, where $\beta\left[\right.$ day $\left.^{-1}\right]$ is an unknown rate constant.

With these linear kinetics, and recognizing that the flow is independent of the Pc concentration, we can separately track the fate of biomass concentrations $C_{i}$ originating from each upslope source cell $i$ (Figure 3B). For an individual source cell, the concentration evolves along the downslope flowpath as:

$$
\frac{\partial\left(h C_{i}\right)}{\partial t}=-\frac{\partial\left(q_{c} C_{i}\right)}{\partial \ell}-h \beta C_{i}
$$

Written in this way, the Source terms in Equation 6 are translated into the boundary conditions on $C_{i}$ at location $i$. To simplify Equation 7, we apply the steady-state approximation referred to in Section 2.2.1, and approximate the flow depth and velocity along $\ell$ between cells $i$ and $j$, with their spatial averages $\bar{h}[\mathrm{~m}]$ and $\overline{u_{i, j}}\left[\mathrm{~m}_{\text {day }^{-1}}\right]$, yielding:

$$
0=-\overline{u_{i, j}} \frac{\partial C_{i}}{\partial \ell}-\beta C_{i}
$$

This differential equation can be solved to identify the concentration of pathogen biomass in the runoff at location $j$, located downstream along the flowpath $\ell$ from source location $i$, that can be attributed to the mobilization of biomass from source $i$ :

$$
C_{i}(\ell)=C_{i o} e^{\frac{-\beta\left(\ell_{j}-\ell_{i}\right)}{\bar{u}_{i, j}}}
$$

where $C_{i o}$ is the boundary condition for this concentration at cell $i$ and represents the storm-averaged biomass concentration generated by mobilizing Pc into the flow at that site. The Sink term at location $j$ associated with biomass originating from $i$ is given by multiplying Equation 9 by the rate constant $\beta$, and can be used to compute the total transport of biomass from source location $i$ to sink location $j$ 
during the storm:

$$
M_{i, j}^{+}=\left(\beta C_{i o} e^{\frac{-\beta\left(\ell_{j}-\ell_{i}\right)}{\bar{u}_{i, j}}}\right) \times\left(\frac{\Delta \ell}{\overline{u_{j}}}\right) \times\left(q_{\text {storm }} A_{i} \phi_{i, j} t_{\text {storm }}\right)
$$

In this expression, $A_{i}\left[\mathrm{~m}^{2}\right]$ is the upslope contributing area which generates runoff that passes through cell $i, \overline{u_{j}}\left[\mathrm{~m} \mathrm{~s}^{-1}\right]$ is the storm-averaged runoff velocity at cell $j$, and $\Delta \ell$ is the travel path length passing through location $j$ (and can be approximated by the grid size $\Delta x$ ). Equation 10 can be interpreted as the product of the rate of biomass deposition (first term), the average residence time of water in cell $j$ (second term), and the total volume of runoff that is routed from $i$ to $j$ over the course of the storm (third term).

\subsubsection{Hydraulic assumptions}

To implement Equations 9 and 10, expressions are needed for the distance $\ell_{j}-\ell_{i}$, as well as the stormaveraged flow velocity and depth terms. We approximate $\ell_{j}-\ell_{i}$ with the Euclidean distance between the points $i$ and $j\left(\chi_{i, j}\right)$. We use Manning's Equation to describe the flow behavior at a point as:

$$
u=K h^{\frac{2}{3}}
$$

Where $K\left[\mathrm{~m}^{\frac{1}{3}} \mathrm{day}^{-1}\right]$ is a kinematic resistance factor (Brutsaert et al., 2005), given by $\sqrt{\text { slope }} / \nu$ where $\nu$ [day $\mathrm{m}^{-\frac{1}{3}}$ ] parameterizes the resistance of the land surface to flow. For the one dimensional flows we consider, flow velocity $u=q_{c} / h$, and for steady conditions, $q_{c}$ depends on the storm averaged rate of runoff production $q_{\text {storm }}$ and the upslope contributing area $A$ :

$$
h=\left(\frac{q_{c}}{K}\right)^{3 / 5}=\left(\frac{q_{\text {storm }} A}{\Delta y K}\right)^{3 / 5}
$$

where $\Delta y$ is again used to approximate the flowpath width. With Equation 11, this expression for $h$ gives the velocity as:

$$
u=K\left(\frac{q_{\text {storm }} A}{K \Delta y}\right)^{\frac{2}{5}}
$$

$u$ can then be used in Equation 10. However, with this substitution, Equation 10 contains two unknown parameters: the linear rate constant $\beta$, and the land surface roughness $\nu$ (forming, with the land surface slope, the kinematic resistance term $K)$.

To facilitate calibration of the model, it is helpful to lump these parameters together in a single term within Equation 10, which we express as $\alpha$ :

$$
M_{i, j}^{+}=\frac{1}{v_{j}} \alpha C_{i o} e^{\frac{-\alpha \chi_{i, j}}{\bar{v}_{i, j}}} \Delta x q_{\text {storm }} A_{i} \phi_{i, j} t_{\text {storm }}
$$


Where $\alpha=\nu^{\frac{3}{5}} \beta$, and $v\left[\mathrm{~m}^{\frac{4}{5}}\right.$ day $\left.^{-\frac{2}{5}}\right]$ represents all terms (other than $\nu$ ) in Equation 13. $v$ can be defined from topography and storm properties. It is computed at cells $i$ and $j$ (giving $v_{i}$ and $v_{j}$ ) and averaged to give $\overline{v_{i, j}}$, an approximation to its spatial mean along the flow path between the cells.

When Equation 14 is summed over all upslope source cells, it gives the total deposition at a cell $j$ with $n$ upslope source cells as a result of an overland runoff event:

$$
M_{j}^{+}=\sum_{i=1}^{n} \frac{1}{v_{j}} \alpha C_{i o} e^{\frac{-\alpha \chi_{i, j}}{\bar{v}_{i, j}}} \Delta x q_{s t o r m} A_{i} \phi_{i, j} t_{s t o r m}
$$

\subsubsection{Concentration boundary condition due to Pc mobilization at a cell}

The only remaining unknown in the transport model is the boundary condition at each source cell $i, C_{i o}$. Source cells are those where Pc biomass areal density $B_{i}\left[\mathrm{~g} \mathrm{~m}^{-2}\right]$ is sufficiently high to cause the host to appear 'infected' (see Section 2.4). At these cells, in the absence of detailed mobilization studies on Pc propagules to guide a more mechanistic representation of mobilization, we assume that each runoff generating event mobilizes all Pc biomass within an "effective depth of interaction" $(\delta, \mathrm{mm})$ which varies with soil type (Ahuja et al., 1981), measured downward from the soil surface. The biomass concentration is assumed to be uniform throughout the root zone. This means that there is a specified total biomass $M_{i}^{-}[\mathrm{g}]$, that will be transported out from each source cell:

$$
M_{i}^{-}=\frac{B_{i} \delta \Delta x \Delta y}{z_{r}}
$$

Mass balance requires that $M_{i}^{-}=\sum_{j=1}^{n} M_{i, j}^{+}$- that is, all biomass originating from $i$ that is deposited to $n$ downslope cells must sum to the mobilized biomass from $i$. By equating this sum (taken from Equation 15) to the right hand side of Equation 16, it is possible to solve for $C_{i o}$, providing that all biomass is deposited along the modeled flowpath $\ell$. The special case where flowpaths extend outside the model domain is addressed in the Appendix A.

With $C_{i o}$ constrained by the mass balance, Equation 14 can be used to find $M_{i, j}^{+}$for each pair of source-sink cells. Runoff events can result in mobilization of biomass from an infected cell, superposed on deposition of biomass into the same cell from infected cells upslope. The net change in biomass density as a result of overland transport $B_{\text {runoff }}\left[\mathrm{g} \mathrm{m}^{-2}\right]$ is given by combining Equation 15 describing the sink behavior of the cell and Equation 16 describing the source behavior of the cell:

$$
B_{\text {runoff }}=\frac{M_{j}^{+}-M_{i}^{-}}{\Delta x \Delta y}
$$

where here the use of both labels $j$ and $i$ emphasizes the potentially dual role any site can have as both a source and sink of Pc. 

$349 \mathrm{~m}^{-2}$.

\subsection{Pathogen growth}

Pathogen biomass density (on a per-area basis, $B$, $\left[\mathrm{g} / \mathrm{m}^{2}\right]$ ) grows following a logistic-type growth equation. The growth rate $r$ varies with soil moisture $s$ and temperature $\left(T_{\text {soil }}\right)$, such that $r=r_{\max }\left(T_{\text {soil }}\right) \times m(s)$. Here, $r_{\max }\left(T_{\text {soil }}\right)$ represents the growth rate of the mycelia under ambient temperature and optimal soil moisture conditions. $r_{\max }$ varies linearly with temperature as $r_{\max }\left(T_{\text {soil }}\right)=r_{0}+\Delta r T_{\text {soil }}$ (Shearer et al., 1987), where $r_{0}$ is the growth rate in optimal soil moisture conditions at $T=0^{\circ} \mathrm{C}$ and $\Delta r\left[{ }^{\circ} \mathrm{C}^{-1}\right]$ is a fitted parameter describing the temperature dependence of pathogen growth. The function $m(s)$ represents the effect of changing soil moisture on pathogen growth rates, which are impaired at very high and very low soil water potentials (Malajczuk \& Theodorou, 1979). From the soil water potentials, we find the relative water content $s$ using the Brooks-Corey water retention curve (Brooks \& Corey, 1964), and follow Thompson et al. (2013) in approximating $m(s)$ with a linear piecewise function, shown in Appendix B. We account for a constant (time and environmentally independent) mortality rate for mycelia $d\left[\right.$ days $\left.^{-1}\right]$. The pathogen growth model at a point is given by:

$$
\frac{\partial B}{\partial t}_{\text {growth }}=\left[r_{\max }\left(T_{\text {soil }}\right) m(s)-d\right] B\left(1-\frac{B}{B_{\max }}\right),
$$

where $B_{\max }$ represents the maximum biomass density that can be sustained at a point, assumed to be constant. Note that the model omits Pc mortality due to freezing (Marçais et al., 1996) as a simplifying measure given the warm temperatures experienced at the case study sites explored here.

\subsection{Pathogen spread}

Pc spread due to the spatial growth of mycelium and dispersal of propagules within the soil is modeled continuously in time and approximated with a diffusive process. The diffusion coefficient is isotropic and is scaled down from its maximum $\left(D_{\max }, \mathrm{m}^{2} \mathrm{day}^{-1}\right)$ by the soil moisture function $m(s)$ to ensure that soil moisture conditions that inhibit Pc growth also inhibit Pc spread. Pathogen transport in overland flow appears as the addition of biomass $B_{\text {runoff }}$ (Equation 17), which is non-zero only at the end of a runoff-producing storm event. The biomass model is then given by:

$$
\frac{\partial B}{\partial t}=\left[r_{\max }\left(T_{\text {soil }}\right) m(s)-d\right] B\left(1-\frac{B}{B_{\max }}\right)+D_{\max } m(s) \nabla^{2} B+B_{\text {runoff }}
$$

Note that the dynamics of the model are independent of the numerical value of $B_{\max }$. We define the threshold for host 'infection' as $0.5 B_{\max }$ (also independently of $B_{\max }$ ), and arbitrarily set $B_{\max }$ to $1 \mathrm{~g}$ 


\section{Model parameterization and tests}

\subsection{Site descriptions}

Two Pc infections, one in a Banksia woodland growing on the deep sands of the Swan Coastal Plain in Western Australia, and one in an Erica heathland located in the Sierra de las Villuercas mountain range in eastern Extremadura, Spain, form case studies where we test whether the model can represent the spatial spread of Pc disease and explore the potential role of overland flow in this spread.

\subsubsection{Western Australian site}

The Western Australian case study site is a Pc infection established before 1950 in Banksia woodlands growing on the flat, deep sands of the Swan Coastal Plain, north of the city of Perth in Western Australia. Wilson et al. (2012) mapped (and ground-truthed) the spatial progression of Pc infection at the site from 1953 - 2008 from aerial imagery, providing the spatial dataset we analyzed. The site has a warm Mediterranean climate with $725 \mathrm{~mm} /$ year precipitation, average summer high temperatures of $32{ }^{\circ} \mathrm{C}$ and average winter low temperatures of $9{ }^{\circ} \mathrm{C}$. Daily climate data (precipitation and temperature) were obtained from the nearby Pearce RAAF Base weather station (Station ID 009053, http://www.bom.gov.au/climate/data/). Daily maximum and minimum temperatures were used to compute potential evaporation via Hargreaves' equation (Hargreaves \& Samani, 1985). Climate gap filling used average temperature data (for the given day of year in all other years), and a satellite weather product (CHIRPS, version 2.0 final) for daily rainfall (Funk et al., 2015). A $5 \times 5$ m, LiDAR-derived DEM for the site (Geoscience Australia, 2015) was interpolated onto a $1 \mathrm{~m}$ grid.

\subsubsection{Spanish site}

The Spanish case study site is a Pc infection established before 1981 in the Erica heathlands of the the Montes de Toledo on the Spanish central plateau. The fairly shallow, poorly drained quartzitic ultisols, and deeply incised landscape (slope gradients of 5\% - 50\%) contrasts sharply with the Western Australian site. Cardillo et al. (2018) mapped disease foci and their expansion from aerial photography at this site to determine spatial progression of disease from 1981 -2012, providing the spatial dataset we used for this site. This site also has a warm Mediterranean climate, with an average of $855 \mathrm{~mm} /$ year precipitation, average summer high temperatures of $32{ }^{\circ} \mathrm{C}$ and average winter low temperatures of $4{ }^{\circ} \mathrm{C}$ based on daily climate data obtained from the nearby Cañamero weather station (Station ID 4334, Agencia Estatal de Meteorología AEMET). The same ET estimation and climate record gap filling procedures were employed as in Western Australia. A $5 \times 5$ m DEM (PNOA-MDT05 2010 CC-BY 4.0 ign.es) for the site was obtained from the Instituto Geográfico Nacional (IGN, Spain) and interpolated onto a $1 \mathrm{~m}$ grid. 


\subsection{Selection of disease patches to model}

We identified isolated disease patches that did not initially intersect roads, bare patches, or other barriers to Pc dispersal. Where patch growth caused the patch to intersect channels or other unvegetated areas, we treated those features as boundaries, forcing Pc biomass to remain zero on the other side of the boundaries. The locations of these features were identified using the D- $\infty$ algorithm to map upslope contributing area, and corroborated against aerial imagery. With these constraints, eight patches (patches a-h) were selected from Warbrook Road in Western Australia. Patch sizes were measured in 1987 and 1992, defining a 5-year time domain for running the model. Seven patches (patches 1-7) were selected from the Spanish observations, three (patches 1-3) measured between 1981 and 1984, and four (patches 4-7) between 2010 and 2012.

\subsection{Numerical implementation}

Within each observed disease patch the model was initialized with $B=B_{\max }$. Soil moisture was initialized using a one year spin-up starting at the end of the dry season, when it was assumed $s=s_{w p}$. The model was implemented on a two-dimensional spatial grid $(1 \mathrm{~m} \times 1 \mathrm{~m})$ that aligned with the DEM grid, using a 1 day time step (we confirmed that results were stable to changes in the time and space grids) such that the model was numerically stable and the model resolution best matched the resolution of the parameterization data for the sites. A centered difference scheme was used for the second-order spatial terms from the diffusion equation. An explicit (forward) scheme was used for time stepping. Open flux boundary conditions were assumed, with one-sided difference schemes used at the spatial boundaries. The D- $\infty$ algorithm was implemented using tools developed by Eddins (2018). Model output, consisting of the Pc biomass density $(B(x, y, t))$ was binarized at a threshold of $B=0.5 B_{\text {max }}$, to allow comparison to mapped infection boundaries (Figure 2D).

\subsection{Parameterization}

In Western Australia, we modeled the $1.5 \mathrm{~m}$ deep root zone containing most Banksia roots (Hill et al., 1994), with a freely-draining bottom boundary (accounting for the, on average, $8 \mathrm{~m}$ of unsaturated sand overlying the water table at this site). For the Spanish sites, we modeled the $0.7 \mathrm{~m}$ deep soil with an impermeable bottom boundary representing a low permeability B horizon (Espejo, 1987). The saturated hydraulic conductivities were set to $3.7 \mathrm{~m}_{\text {day }}{ }^{-1}$ and $64.8 \mathrm{~m} \mathrm{day}^{-1}$ for the Western Australia and Spain sites, respectively, based on prior local studies (Gómez-Paccard et al., 2015; Salama et al., 2005). The remaining parameters for the soils $\left(n, s^{*}\right.$, and $\left.s_{w p}\right)$ were taken from Laio et al. (2001) using the "sand" for Western Australia and "sandy loam" for Spain. These soils types were used to determine the effective depth of interaction $(\delta)$ following Ahuja et al. (1981). 
The fractional pathogen growth rate at $0{ }^{\circ} \mathrm{C}\left(r_{0}\right)$ was set to -0.171 day $^{-1}$ (Malajczuk \& Theodorou, 1979). Given the relatively shallow soil depths, we approximated $T_{\text {soil }}$ with $T_{\text {air }}$ at all times for both sites. The moisture dependence of the growth $(m(s))$ was estimated as a piecewise function based on experimental data from Malajczuk and Theodorou (1979) (Appendix B.1).

\subsection{Assessment of Soil Water Balance}

Since the sites lack contemporaneous hydrological data, direct validation of the modeled soil moisture and runoff was not possible. However, comparison to other data sources still has the potential to assess that the modeling approach was resulting in soil moisture values and runoff predictions that were characteristic of the study locations. Given the exploratory aim of this study, these confirmations of characteristic model behavior provide confidence in being able to discriminate between the tested hypotheses, even when direct validation that would be necessary for more detailed predictive studies is not possible (Harmel et al., 2014; Rastetter, 2017). For Mediterranean climates such as those of the two study sites, the probability distribution function (PDF) of soil moisture values is predictable and acts as a reasonable way to summarize the soil moisture regime of a given location (Dralle \& Thompson, 2016; Laio et al., 2001). Thus, comparison of soil moisture PDFs from the model predictions to those from other sources during climatologically-similar years, provides a way of assessing if the soil moisture predictions, including occurrences of saturation leading to runoff, are realistic for the respective study sites. For the Western Australia site, we compared model output to soil moisture measurements made to a depth of $160 \mathrm{~cm}$ at the Gingin OzFlux site (OzFlux Network, n.d.) which is also located on Bassendean sands in a Banksia woodland in the same rainfall zone. For the Spanish site, there are no measurements available from any similar sites so we used Soil Moisture Active Passive (SMAP) estimates for the water content in the uppermost $5 \mathrm{~cm}$ of soil (Entekhabi et al., 2010). A direct comparison of surface soil moisture to depth-averaged moisture across the soil column is challenging, as the surface would be expected to dry out more readily than the root zone average. To better compare the model and SMAP, we therefore removed summer periods (June through September when SMAP was uniformly minimal) for both the SMAP and modeled data. Since neither of these other data sources were operational during the same time periods as the pathogen observation data, we consider climatoligically-similar years: 2015 for the Gingin site and 2018 for the SMAP data. Due to differences in the assumptions of minimum and maximum soil moisture values across the different data sources, both the Gingin and SMAP data are scaled to the same range as the modeled data for the respective sites.

\subsection{Calibration}

Four model parameters needed to be calibrated to run the model: the mortality rate $(d)$, diffusion coefficient $\left(D_{\max }\right)$, temperature dependence of growth $(\Delta r)$, and the overland transport parameter $(\alpha)$. 
The first three are shared for all patches within a study site, whereas the $\alpha$ parameter is calibrated to each hillslope to account for potential variation in surface cover. We estimated plausible ranges for the pathogen mortality rate $(d)$ from Hwang and Ko (1978), of growth temperature dependence $\Delta r$ from Malajczuk and Theodorou (1979), Thompson et al. (2014), and of maximum diffusion coefficient $D_{\max }$ from patch growth rates in the upslope direction (assumed to be due to purely diffusive transport). The combined pathogen sink rate constant and land surface roughness parameter $\alpha$ is poorly constrained a priori, so several orders of magnitude of $\alpha$ values were screened to find a plausible range for calibration. Once calibrated, the values for the site-wide parameters were compared as an indication of whether the model was predicting similar dynamics for processes which could be expected to be conserved across locations, or if there were differences that could be a result of calibrated parameters compensating for other errors or missing processes in the model that varied between sites.

\subsubsection{Calibration metrics}

Model calibration aimed to maximize agreement between mapped observations of the spatial extent of Pc infection and predictions for each patch, focusing on four features: the orientation of the disease patch, its eccentricity, the length of its major axis, and an areal growth increment. Differences between these features and observations were computed, and standardized to lie between 0 (complete disagreement) and 1 (perfect agreement). Fitting, differencing, and standardization of the features are described in the Appendix C. The four standardized scores were averaged to give a composite score for each modeled patch.

\subsubsection{Calibration and Model Experiments}

We calibrated the growth and diffusion related parameters $\Delta r, D_{\max }$, and $d$ together for each site (i.e. these parameters were common to every patch at the site). We calibrated two different cases of the mdoel for each site: one in which overland flow transport of Pc was omitted (the "diffusion optimized" case), and one in which overland flow transport of Pc was included (the overland transport case). In the diffusion optimized case, we ran the calibration in two stages - firstly sampling parameter values from a coarse factorial grid spanning the range of plausible values, and secondly sampling over a finer range of values identified after the first step. No constraints were placed upon the parameter values, and the refinement process was continued until an optimum value of each parameter was found, such that changing the value of any parameter while holding the others constant resulted in a decrease in the mean composite score. In the first phase of calibration for the overland transport case, combinations of site-wide parameters were tested and the scores averaged for a range of $\alpha$ values. As with the previous calibration case, this was done first with a coarse factorial grid and then refined until the optimum value of each was found. Once the values of these site-wide parameters were determined, we then further 
calibrated $\alpha$ individually for each patch to account for differences in surface cover across the landscape.

We used the two versions of the calibrated model to firstly identify whether, and at which sites, including overland transport resulted in an improved description of patch growth geometry relative to a model with only diffusive spread included. There are several possible outcomes from these model experiments. For a site with no overland flow, there is no differentiation between the two calibration cases. The overall model performance provides an indicator of how well the model predicts Pc disease spread based only on local water balance and its impacts on pathogen growth and diffusion. For a site where overland flow occurs, differences in model predictions would be expected between the two calibration cases. If adding the overland flow mechanism does not improve model predictions of disease spread, then disease spread is not impacted by the modeled overland flow. Conversely, if adding a representation of overland flow improves the predictions of disease spread relative to a calibrated model where spread is purely diffusive, this serves as evidence that Pc was transported by overland flow. In a second phase of model experiments for those sites where overland transport did improve the model performance, we re-ran the calibrated (overland flow) models, but 'turned off' overland transport. The differences in predictions with and without overland flow transport provide a measure of the importance of diffusive versus overland flow driven spread of Pc. The differences in predicted disease spread geometry and rate measure the 'importance' of the overland transport process for Pc spread. These comparisons from the different versions of the model are summarized in Figure 4.

\section{Results}

This results section addresses the predictions of the soil moisture model (Figure 5), the calibration values obtained for the 'full' model at each site (Table 3), and the performance of the calibrated model with and without overland flow in reproducing observed patterns of disease spread (Figures 6 and 7).

From the soil water balance component of the model, the water content of the soil at the Western Australia site was predicted to be generally low with no overland flow occurring (Figure 5A). The distribution of soil moisture values measured at the Gingin OzFlux site is highly comparable to that predicted by the model, with both exhibiting a bimodal distribution. By contrast, occasional episodes of overland flow (on average 10 per year during the study periods) were predicted at the Spanish site, generated in all cases as saturation excess (Figure 5B). These same data with the summer period (JuneSeptember) removed are shown in Figure 5C along with the SMAP data from 2018 with the same summer months removed in order to enable comparison to the limited depth resolution of the SMAP data. From the comparison, it can be seen that there are instances of saturation at the uppermost layer supporting this prediction of saturation excess overland flow, even though the SMAP data are generally more skewed towards drier conditions as would be expected for the uppermost surface layer as compared to the water 
content predicted for the whole soil column as in our model. However, the model captured the same overall trimodal distribution of soil moisture values as is seen in the SMAP data.

Since Pc is reported to be genetically very similar in infections occurring worldwide (Linde et al., 1999), it might be expected that properties related to the pathogen growth processes would be similar for the Australian and Spanish sites. Reassuringly, calibration of the 'full' model (including overland flow transport), resulted in very similar estimates of the free growth model parameters $d$ (mortality rate) and $\Delta r$ (sensitivity of growth rate to temperature), as shown in Table 3 . The remaining two calibration parameters relate to spatial spread processes. One, the $\alpha$ parameter is idiosyncratic to each individual flow path downslope of the infected patches, and would be expected to vary: these fitted $\alpha$ values are reported in Appendix G. The remaining parameter is the diffusivity $D_{\max }$, which parameterizes the rates of local spread by zoocytes and mycelial growth. Under idealized conditions, a diffusion coefficient scales with the square of the velocity of patch expansion (Okubo \& Levin, 2013). Assuming that upslope expansion of the patches is uninfluenced by transport in surface flow, the velocity of these disease fronts can be used to estimate the diffusion coefficient. During the observed periods, the disease front at the Western Australia site moved at an average rate of approximately $0.7 \mathrm{~m} \mathrm{yr}^{-1}$ (Zdunic et al., 2010) and the upslope growth rate at the Spanish site was $0.16 \mathrm{~m} \mathrm{yr}^{-1}$ (Cardillo et al., 2018) and suggests that the diffusion coefficient for the Australian site should be approximately $16 \times$ greater than that at the Spanish site. This sixteen-fold scaling was preserved in the calibration, as shown in Table 3. A simple explanation for the different rates of lateral spread at the two sites may lie in the different size and root extent of the infected species: the Banksia in Western Australia have extensive shallow lateral roots (Hill et al., 1994) extending several meters from the tree stem. Conversely, the Erica umbellata shrubs at the Spanish site are smaller with a less obviously dimorphic and laterally extensive root system (Silva \& Rego, 2003). Thus, the rhizosphere in the Western Australian site may be particularly favorable to spatial spread of Pc.

Representative model predictions of disease spread at the two sites are shown in Figure 6, which shows model predictions for select patches, one where the model performed relatively well and one where the model performed relatively poorly, from Western Australia (panels A and B) and Spain (panels C and D). Appendices $\mathrm{E}$ and $\mathrm{F}$ show equivalent results for all other modeled patches . The performance of the model in terms of the composite scores for each modeled patch are shown in panels E and F. Because no overland flow occurred in Western Australia (Figure 5A), there was no differentiation between the versions of the model with and without overland transport of Pc. The model made very good predictions of Pc spread as can be seen visually in Figure 6 panels A and B which show that predicted disease extents captured the shape and area of the mapped disease. This good performance is reflected in the mean value of the composite score of 0.856 across the 8 patches (Figure $6 \mathrm{E}$ ). The model was not able to capture the exact borders of the disease patches, which are generally uneven and asymmetric in the 
observed data.

Intermittent episodes of overland flow were predicted for the Spanish site (Figure 5B). Figures $6 \mathrm{C}$ and D show model results for two of the modeled Pc disease patches at the Spanish site. The two patches were selected to show an example of relatively poor model performance (D) with limited sensitivity to changing the description of Pc transport, and relatively strong model performance $(\mathrm{C})$ with strong sensitivity to changing the Pc transport description. In the subsequent subplots ( $\mathrm{E}$ and $\mathrm{F}$ ), those relatively insensitive, poorly-performing patches are shown with blue dots, with the higher-performing, more sensitive patches shown with red dots. For those patches where the Pc spread was sensitive to the transport process, as in panel D, diffusion alone was insufficient to reproduce the observed growth rates in the patch, and tended to produce (as expected) primarily isotropic predictions of Pc disease spread. Incorporating transport in overland flow improved the ability of the model to simulate the extent, anisotropy, and specific shape of patches like this one. The model performance, in terms of the composite score for the optimized model containing overland flow, was also excellent, and very similar to that in the Western Australian case study site, at 0.864 (Figure 6E). The importance of including Pc spread via overland flow at the Spanish site is illustrated in Figure 6F. In comparison to the model optimized for diffusive transport only, these scores increased by an average of 0.15 across the modeled patches. This average includes two patches (shown in blue in Panels E and F, and including the example shown in Panel D of Figure 6) which were essentially insensitive to the inclusion of overland flow at the Spanish site. These patches had the lowest composite scores in the overland transport model. As discussed below, lack of well-resolved topographic data may be responsible for the relatively poor performance of the model at these patches, and their insensitivity to adding overland flow transport.

In the remainder of the patches (red dots), the mean composite score was higher (0.876 for the overland transport model), and the inclusion of overland transport resulted in greater improvements in model performance relative to a diffusion optimized model (an increase of 0.204). As might be expected, the overland flow model performance was notably degraded when overland flow transport was turned off, again with the exception of the two problematic sites shown in blue in Figure $6 \mathrm{~F}$. In the other patches, excluding overland transport lowered the composite score by an average of 0.220 . This difference between having overland transport turned on and off in terms of patch areal growth predictions is shown in Figure 7. While the specific error in predicted disease spread varies by patch, in several cases the underestimation of disease spread using a diffusion-only model is substantial. On average, the growth areas predicted when overland flow was included were 3.6 times larger than those predicted using diffusion alone (overland off case). Qualitatively, this can be seen in the differences between the two cases in Figure 6C and others in Appendix F, where removing overland flow transport processes resulted in patch predictions that were smaller and more isotropic than compared to the overland flow predictions which better captured the magnitude and directionality of growth. 


\section{Discussion and Conclusions}

The aim of this study was to explore the potential role of Pc transport in overland flow as controlling the spread of Pc disease. The Western Australian site provided a control site in which soils did not become persistently saturated and no overland flow was formed, and in which the diffusion only model provided a good representation of the relatively isotropic disease spread around pre-existing patches. This control site provides insights that are useful when interpreting the model experiments at the Spanish site: (i) it provides an opportunity to sense-check the behavior of the soil moisture component of the model using a comparison to measured soil moisture data (albeit from a different time period) at the climatically, ecologically, and edaphically similar Gingin flux tower site, which suggested that the soil moisture PDF and its dynamics are well represented by the model, (ii) it allows an evaluation of the performance of the growth and diffusion components of the model in the absence of overland flow transport - an evaluation that suggests that these components of the model reasonably capture disease spread dynamics, and (iii) it provides one independent estimate of the values of the common calibration parameters $(d$ and $\Delta r)$ that might be expected to concur across multiple Pc infection sites, and which proved to indeed be very similar to those independently estimated at the Spanish sites. The main limitations of the diffusive model performance at the Western Australian site pertained to heterogeneities in the location of the patch edges in Western Australia. This lack of precise agreement between model and observation on the patch boundaries is unsurprising: it is likely to be influenced by small-scale heterogeneities in soil properties or in the root network of host species, and by the difficulty of delineating the occurrence of disease/undiseased areas precisely at patch boundaries.

The hydrological conditions at the the Spanish site contrast those in Western Australia. Here the results suggest that (i) the soil moisture model reasonably captures the dynamics of soil moisture variations at the site, using comparisons to surface soil moisture from SMAP during a climatically similar year, (ii) that saturated conditions occur sporadically at the site, resulting in the prediction of an average of ten incidents of saturation excess overland flow per year, (iii) that the good performance of the diffusion-only transport model at the Western Australian site is not maintained at the Spanish site, but fails to reproduce either the morphology or the rate of disease spread, that (iv) the simple representation of overland flow transport rectifies these difficulties for most of the modeled disease patches, as shown in Figure 6, and that (v) when it does so, the calibrated growth parameters for Pc are very similar to those in Western Australia, and (vi) the calibrated diffusion parameters are consistent with the observed differences in the rates of spread between the sites, if isotropic spread rates in Western Australia are compared with upslope spread rates in Spain. These findings suggest that Pc transport in overland flow needs to be considered as a potential driver of spread in the Spanish site. Excluding such advective transport at this site would underestimate Pc spread rates by an average of $350 \mathrm{~m}^{2} /$ year per patch (Figure 7): suggesting that overland transport of Pc can greatly accelerate pathogen spread. 
Several of these findings are also reassuring with respect to the suitability of the admittedly simple models used. For example, large errors in water balance (e.g. due to omitted hydrological processes such as interception) would be expected to impact predictions of Pc growth rates, and thus be 'absorbed' by the calibrated growth parameters, which would lead to their values diverging between the sites. The fact that no large divergence occurs, along with the reasonable depiction of the soil moisture PDF, provides a useful 'sense check' on the performance of the hydrological model at local scales. Similarly, the fact that the calibrated diffusion coefficients preserve the scaling expected from local growth rates in the absence of overland flow suggests that the model calibration was able to reasonably separate diffusive from advective pathogen transport at the Spanish site. Finally, we undertook a sensitivity analysis on the results to determine how robust were the conclusions about the role of overland transport in pathogen spread. As outlined in Appendix H, these conclusions were unchanged as model parameters were altered by $\pm 20 \%$. This suggests that even given the uncertainties arising from the data limitations of the sites, the data and modeling suggest that overland flow must be important mechanism for pathogen spread.

In spite of these overall positive results, two of the modeled disease patches at the Spanish site, were essentially insensitive to the inclusion or exclusion of overland flow. We tentatively attribute this lack of sensitivity to the poor resolution of the topographic data used: for example, Patch 2 (the insensitive patch illustrated in Figure 6C) is located on and grows astride a ridgeline: the local topography at this area may not be well resolved in the $5 \mathrm{~m} \times 5 \mathrm{~m}$ DEM. The simulated growth of this patch is biased towards the left-hand, relative to the nearly symmetrical growth of the observed patch. Such bias could easily result from errors in the location of the ridge crest relative to the patch boundaries. Lack of resolution in the DEM may also be responsible for simulations in which the model does not represent the shape of the Pc patch well (e.g. Patches 1 and 4). Other model limitations, including missing smallscale heterogeneity in hydrological processes such as interception or surface detention storage, omitted transport pathways including vector spread, and transport in water moving within the soil could also be contributing to the discrepancies. We note that where the model performance was weakest, it typically underestimated Pc spread, which would be consistent with additional transport vectors playing a role in local spread.

In spite of these limitations, the results demonstrate the feasibility of describing the spatiotemporal dynamics of Pc spread provided information about the rhizosphere and transport mechanisms is available. The study is also illustrative of the potential for hydrological processes to act as a driver of disturbance caused by plant pathogens, with the saturation excess overland runoff generation at the Spanish site introducing a relatively rapid and long-distance transport mechanism for Pc. Although this study focuses on the role of saturation excess runoff generation as the main feasible process at the study sites, other mechanisms that generate overland flow would be expected to have a similar impact on disease spread.

Models of pathogen growth and spread such as the one presented here could be readily incorporated 
into scenario planning around water and drainage management - for example by coupling this model to distributed hydrological models already in use. However, this would require calibration and parameterization that might not be feasible for many practitioners and, depending on site characteristics, may require the representation of additional processes in the model, as noted in the description of the model. Alternatively, recognizing that many areas with active Pc infections might have limited site data, some of the key dynamics revealed in this study can be used to suggest ways to augment Pc risk assessments using more readily available data to account for potential transport via overland flow, in addition to the simple annual climate, soil, and slope metrics that are currently used to describe disease risk. For example, Porporato et al. (2004) showed that the probability of soils saturating is controlled by two dimensionless ratios: the soil water holding capacity to the average storm depth, and the ratio of the mean rate of water input (e.g. average storm depth multiplied by average time between storms) to the rate of water loss by evaporation. These ratios can be readily calculated (on a seasonal basis) to identify the likelihood of saturation, and therefore overland flow events. Where saturation is more topographically than edaphically controlled, metrics such as the topographic wetness index (TWI) (Beven \& Kirkby, 1979), could be incorporated into risk assessments. For infiltration excess dominated sites, intensityfrequency-duration type assessments and improved models of infiltration rate could be used for similar risk assessments. Flow routing algorithms (like the one used in this model) could be used to assess how far disease propagules mobilized at a given site in a landscape could be transported if overland flow does occur. Together, these kinds of measures suggest the potential for hydrologically informed disease risk assessments to better identify sites at high risk of supporting new disease, as well as sites at high risk of spreading disease to new locations. Such identification could improve the triaging and management of $\mathrm{Pc}$ risk relative to existing approaches that typically do not consider overland flow transport mechanisms.

Pc already presents a major risk to plant communities around the globe, and this threat is likely to increase as climate change enables the expansion of Pc into new regions. This study demonstrated that hydrological transport of Pc propagules is necessary to explain observed patterns of Pc disease spread in a steep, saturation-excess producing site, using a parsimonious modeling approach. However, more detailed coupled modeling linking the within-storm processes of runoff generation and disease propagule mobilization and transport is currently inhibited by two main knowledge gaps. The first is that Pc disease research sites have not, to date, hosted hydrological observational studies or field experiments. In spite of the practical factors relating to Pc quarantine and hygiene that make such studies challenging, the likely importance of transport in overland flow events implied by the present analysis suggests that coupling such measurements with plant pathology would be rewarding at such sites. The second knowledge gap relates to the current lack of mechanistic insight into how infectious Pc material is mobilized from soil by flowing water, how it is transported in that water, and how it is deposited or trapped during its transport. As suggested by mechanistic studies of fluvial transport of biological tracers (e.g. eDNA), these processes 
may be idiosyncratic (Jerde et al., 2016; Shogren et al., 2017). Thus future research in experimental (e.g. column, flume or tank scales) and field settings would provide useful insights into mechanisms and allow the refinement, testing, and improvement of the parsimonious modeling framework explored here.

\section{Acknowledgements}

We thank Janine Kinloch, Barbara Wilson, Katherine Zdunic, and the Western Australia Department of Biodiversity, Conservation and Attractions (DBCA) for providing the disease mapping data for the site in Western Australia. Soil moisture data from the Gingin Ozflux site was provided courtesy of the Terrestrial Ecosystem Research Network (TERN), an Australian Government NCRIS enabled research infrastructure project. This work was supported by a National Science Foundation Graduate Research Fellowship [Grant No. DGE 1752814 to JVW]; the Junta de Extremadura [Grant No. GR18079 to EA]; the Spanish Agencia Estatal de Investigación [Grant No. FIS2016-76359-P (partially financed with FEDER funds) to EA]; and the National Institute of Agricultural Research of Spain [Grant No. INIA RTA 2014-00063-C01 to EC]. Compiled patch data and climate data used in the model and collected from sources as discussed in the text are available at http://www.hydroshare.org/resource/a010a9c248284240a44180d339a2cba2/. All model code is available at https://github.com/jvwilkening/Pc_Spread_Model.

\section{References}

Ahuja, L. R., Sharpley, A. N., Yamamoto, M., \& Menzel, R. G. (1981). The Depth of Rainfall-Runoff-Soil Interaction as Determined by 32P. Water Resources Research, 17(4), 969-974.

Andow, D., Kareiva, P. M., Levin, S. A., \& Okubo, A. (1990). Spread of invading organisms. Landscape Ecology, 4(2-3), 177-188.

Australian Bureau of Meteorology. (2016). Design rainfall data system [Accessed: 2020-07-10].

Batini, F., Black, R., Byrne, J., Clifford, P., Et al. (1980). An examination of the effects of changes in catchment condition on water yield in the wungong catchment, western australia. Australian Forest Research, 10(1), 29-38.

Benjamin, M., \& Newhook, F. (1982). Effect of glass microbeads on phytophthora zoospore motility. Transactions of the British Mycological Society, 78(1), 43-46.

Bergot, M., Cloppet, E., Pérarnaud, V., Déqué, M., Marçais, B., \& Desprez-Loustau, M.-L. (2004). Simulation of potential range expansion of oak disease caused by phytophthora cinnamomi under climate change. Global Change Biology, 10(9), 1539-1552.

Beven, K. J., \& Kirkby, M. J. (1979). A physically based, variable contributing area model of basin hydrology. Hydrological Sciences Journal, 24(1), 43-69. 
Botter, G., Zanardo, S., Porporato, A., Rodriguez-Iturbe, I., \& Rinaldo, A. (2008). Ecohydrological model of flow duration curves and annual minima. Water resources research, 44(8).

Boyer, J. S. (1995). Biochemical and biophysical aspects of water deficits and the predisposition to disease. Annual Review of Phytopathology, 33(1), 251-274.

Brasier, C. M. (1996). Phytophthora cinnamomi and oak decline in southern europe. environmental constraints including climate change, In Annales des sciences forestieres. EDP Sciences.

Brooks, R., \& Corey, T. (1964). Hydraulic properties of porous media. Hydrology Papers, Colorado State University, 24, 37.

Brutsaert, W. Et al. (2005). Hydrology: An introduction. Cambridge University Press.

Burgess, T. I., Scott, J. K., Mcdougall, K. L., Stukely, M. J., Crane, C., Dunstan, W. A., Brigg, F., Andjic, V., White, D., Rudman, T., Et al. (2017). Current and projected global distribution of phytophthora cinnamomi, one of the world's worst plant pathogens. Global Change Biology, 23(4), 1661-1674.

Cardillo, E., Acedo, A., \& Abad, E. (2018). Topographic effects on dispersal patterns of phytophthora cinnamomi at a stand scale in a spanish heathland. PloS one, 13(3), e0195060.

Chakraborty, S., Tiedemann, A., \& Teng, P. S. (2000). Climate change: Potential impact on plant diseases. Environmental pollution, 108(3), 317-326.

Clapp, R. B., \& Hornberger, G. M. (1978). Empirical equations for some soil hydraulic properties. Water resources research, 14 (4), 601-604.

Colhoun, J. (1973). Effects of environmental factors on plant disease. Annual Review of Phytopathology, $11(1), 343-364$.

Commonwealth of Australia. (2014). Background: Threat abatement plan for disease in natural ecosystems caused Phytophthora cinnamomi (tech. rep.).

Cook, R., \& Papendick, R. (1972). Influence of water potential of soils and plants on root disease. Annual Review of Phytopathology, 10(1), 349-374.

Crist, C., \& Schoeneweiss, D. (1975). The influence of controlled stresses on susceptibility of european white birch stems to attack by botryosphaeria dothidea. Phytopathology, 65(4), 369-373.

Cunniffe, N. J., \& Gilligan, C. A. (2008). Scaling from mycelial growth to infection dynamics: a reaction diffusion approach. Fungal Ecology, 1(4), 133-142. https://doi.org/10.1016/j.funeco.2008.10.007

Dawson, P., \& Weste, G. (1985). Changes in the distribution of phytophthora cinnamomi in the brisbane ranges national park between 1970 and 1980-81. Australian Journal of Botany, 33(3), 309-315.

Desprez-Loustau, M.-L., Marçais, B., Nageleisen, L.-M., Piou, D., \& Vannini, A. (2006). Interactive effects of drought and pathogens in forest trees. Annals of forest science, 63(6), 597-612.

Dickenson, S., \& Wheeler, B. (1981). Effects of temperature, and water stress in sycamore, on growth of cryptostroma corticale. Transactions of the British Mycological Society, 76(2), 181-185. 
Dralle, D. N., \& Thompson, S. E. (2016). A minimal probabilistic model for soil moisture in seasonally dry climates. Water Resources Research, 52(2), 1507-1517.

Dunne, T., \& Black, R. D. (1970). Partial area contributions to storm runoff in a small new england watershed. Water resources research, 6(5), 1296-1311.

Eddins, S. (2018). Upslope area functions.

Entekhabi, D., Njoku, E. G., O’Neill, P. E., Kellogg, K. H., Crow, W. T., Edelstein, W. N., Entin, J. K., Goodman, S. D., Jackson, T. J., Johnson, J., Et al. (2010). The soil moisture active passive (smap) mission. Proceedings of the IEEE, 98(5), 704-716.

Espejo, R. (1987). The soils and ages of the "raña" surfaces related to the villuercas and altamira mountain ranges (western spain). Catena, 14 (5), 399-418.

Ferrin, D., \& Stanghellini, M. (2006). Effect of water potential on mycelial growth and perithecial production of monosporascus cannonballus in vitro. Plant pathology, 55(3), 421-426.

Flower, C. E., \& Gonzalez-Meler, M. A. (2015). Responses of temperate forest productivity to insect and pathogen disturbances. Annual review of plant biology, 66, 547-569.

Funk, C., Peterson, P., Landsfeld, M., Pedreros, D., Verdin, J., Shukla, S., Husak, G., Rowland, J., Harrison, L., Hoell, A., Et al. (2015). The climate hazards infrared precipitation with stations-a new environmental record for monitoring extremes. Scientific data, 2, 150066.

Gamage, S., Hewa, G., \& Beecham, S. (2015). Modelling hydrological losses for varying rainfall and moisture conditions in south australian catchments. Journal of Hydrology: Regional Studies, 4 , $1-21$.

Geoscience Australia. (2015). Digital elevation model (dem) of australia derived from lidar 5 metre grid.

Gómez-Paccard, C., Hontoria, C., Mariscal-Sancho, I., Pérez, J., León, P., González, P., \& Espejo, R. (2015). Soil-water relationships in the upper soil layer in a mediterranean palexerult as affected by no-tillage under excess water conditions-influence on crop yield. Soil and Tillage Research, $146,303-312$.

Green, W. H., \& Ampt, G. (1911). Studies on soil phyics. The Journal of Agricultural Science, 4(1), $1-24$.

Guswa, A. J., Celia, M. A., \& Rodriguez-Iturbe, I. (2002). Models of soil moisture dynamics in ecohydrology: A comparative study. Water Resources Research, 38(9), 5-1.

Hardham, A. R., \& Blackman, L. M. (2018). Phytophthora cinnamomi. Molecular plant pathology, 19(2), 260-285.

Hargreaves, G. H., \& Samani, Z. A. (1985). Reference crop evapotranspiration from temperature. Applied engineering in agriculture, 1(2), 96-99.

Harmel, R., Smith, P., Migliaccio, K., Chaubey, I., Douglas-Mankin, K. R., Benham, B., Shukla, S., Muñoz-Carpena, R., \& Robson, B. J. (2014). Evaluating, interpreting, and communicating per- 
formance of hydrologic/water quality models considering intended use: A review and recommendations. Environmental modelling \& software, 57, 40-51.

Hill, T., Tippett, J., \& Shearer, B. (1994). Invasion of bassendean dune banksia woodland by phytophthora cinnamomi. Australian Journal of Botany, 42(6), 725-738.

Horton, R. E. (1933). The role of infiltration in the hydrologic cycle. Eos, Transactions American Geophysical Union, 14(1), 446-460.

Hwang, S. C., \& Ko, W. H. (1978). Biology of chlamydospores, sporangia, and zoospores of Phytophthora cinnamomi in soil, 726-731.

Jerde, C. L., Olds, B. P., Shogren, A. J., Andruszkiewicz, E. A., Mahon, A. R., Bolster, D., \& Tank, J. L. (2016). Influence of stream bottom substrate on retention and transport of vertebrate environmental dna. Environmental science \& technology, 50(16), 8770-8779.

Jung, T., Colquhoun, I., \& Hardy, G. S. J. (2013). New insights into the survival strategy of the invasive soilborne pathogen p hytophthora cinnamomi in different natural ecosystems in w estern a ustralia. Forest Pathology, 43(4), 266-288.

Jung, T., \& Dobler, G. (2002). First report of littleleaf disease caused by phytophthora cinnamomi on pinus occidentalis in the dominican republic. Plant disease, 86(11), 1275-1275.

Kinal, J., Shearer, B., Fairman, R., Et al. (1993). Dispersal of phytophthora cinnamomi through lateritic soil by laterally flowing subsurface water. Plant Disease, 77(11), 1085-1090.

Kliejunas, J. T., \& Ko, W. H. (1976). Dispersal of Phytophthora cinnamomi on the Island of Hawaii. Ecology and Epidemiology, 66, 457-460 found zoospores of PC in runoff.

Laio, F., Porporato, A., Ridol, L., \& Rodriguez-iturbe, I. (2001). Plants in water-controlled ecosystems : active role in hydrologic processes and response to water stress II . Probabilistic soil moisture dynamics, 24 .

Larsen, L. G., Eppinga, M. B., Passalacqua, P., Getz, W. M., Rose, K. A., \& Liang, M. (2016). Appropriate complexity landscape modeling. Earth-science reviews, 160, 111-130.

Larsen, L. G., Thomas, C., Eppinga, M., \& Coulthard, T. (2014). Exploratory modeling: Extracting causality from complexity. Eos, Transactions American Geophysical Union, 95(32), 285-286.

Linde, C., Drenth, A., \& Wingfield, M. J. (1999). Gene and genotypic diversity of phytophthora cinnamomi in south africa and australia revealed by dna polymorphisms. European Journal of Plant Pathology, 105(7), 667-680.

Lowe, S., Browne, M., Boudjelas, S., \& De Poorter, M. (2000). 100 of the world's worst invasive alien species: A selection from the global invasive species database (Vol. 12). Invasive Species Specialist Group Auckland. 
Madar, Z., Solel, Z., Kimchi, M., Et al. (1989). Effect of water stress in cypress on the development of cankers caused by diplodia pinea f. sp. cupressi and seiridium cardinale. Plant Disease, 73(6), 484-486.

Malajczuk, N., \& Theodorou, C. (1979). Influence of water potential on growth and cultural characteristics of phytophthora cinnamomi. Transactions of the British Mycological Society, 72(1), 1518.

Marani, M., Silvestri, S., Belluco, E., Ursino, N., Comerlati, A., Tosatto, O., \& Putti, M. (2006). Spatial organization and ecohydrological interactions in oxygen-limited vegetation ecosystems. Water resources research, $42(6)$.

Marçais, B., Dupuis, F., \& Desprez-Loustau, M. (1996). Modelling the influence of winter frosts on the development of the stem canker of red oak, caused by phytophthora cinnamomi, In Annales des sciences forestières. EDP Sciences.

McLaughlin, B. C., Ackerly, D. D., Klos, P. Z., Natali, J., Dawson, T. E., \& Thompson, S. E. (2017). Hydrologic refugia, plants, and climate change. Global Change Biology, 23(8), 2941-2961.

Milly, P. (1994). Climate, soil water storage, and the average annual water balance. Water Resources Research, 30(7), 2143-2156.

National Heritage Trust and Environment Australia. (2001). Threat abatement plan for dieback caused by the root-rot fungus Phytophthora cinnamomi (tech. rep.).

Okubo, A., \& Levin, S. A. (2013). Diffusion and ecological problems: Modern perspectives (Vol. 14). Springer Science \& Business Media.

Oudemans, P. V. (1999). Phytophthora species associated with cranberry root rot and surface irrigation water in new jersey. Plant Disease, 83(3), 251-258.

OzFlux Network. (n.d.). Gingin flux station. Australian Terrestrial Ecosystem Research Network (TERN).

Park, A. W., Gubbins, S., \& Gilligan, C. A. (2001). Invasion and persistence of plant parasites in a spatially structured host population. Oikos, 94(1), 162-174.

Philip, J. R. (1957). The theory of infiltration: 4. sorptivity and algebraic infiltration equations. Soil science, $84(3), 257-264$.

Podger, F. (1972). Phytophthora cinnamomi, a Cause of Lethal Disease in Indigenous Plant Communities in Western Australia. Phytopathology, 62, 972-981.

Porporato, A., Daly, E., \& Rodriguez-Iturbe, I. (2004). Soil water balance and ecosystem response to climate change. The American Naturalist, 164(5), 625-632.

Rastetter, E. B. (2017). Modeling for understanding v. modeling for numbers. Ecosystems, 20(2), 215221.

Reeser, P. W., Sutton, W., Hansen, E. M., Remigi, P., \& Adams, G. C. (2011). Phytophthora species in forest streams in oregon and alaska. Mycologia, 103(1), 22-35. 
Rietkerk, M., Boerlijst, M. C., van Langevelde, F., HilleRisLambers, R., de Koppel, J. v., Kumar, L., Prins, H. H., \& de Roos, A. M. (2002). Self-organization of vegetation in arid ecosystems. The American Naturalist, 160(4), 524-530.

Ristaino, J. B., \& Gumpertz, M. L. (2000). New frontiers in the study of dispersal and spatial analysis of epidemics caused by species in the genus phytophthora. Annual Review of Phytopathology, $38(1), 541-576$.

Salama, R. B., Silberstein, R., \& Pollock, D. (2005). Soils characteristics of the bassendean and spearwood sands of the gnangara mound (western australia) and their controls on recharge, water level patterns and solutes of the superficial aquifer. Water, Air, \& Soil Pollution: Focus, 5(1-2), 3-26.

Schober, B., \& Zadoks, J. (1999). Water and temperature relations of softrot bacteria: Growth and disease development. Annals of applied biology, 134(1), 59-64.

Schofield, N., Stoneman, G., \& Loh, I. (1989). Hydrology of the jarrah forest, In The jarrah forest. Springer.

Shea, S., Shearer, B., Tippett, J., \& Deegan, P. (1983). Distribution, reproduction, and movement of phytophthora cinnamomi on sites highly conducive to jarrah dieback in south western australia. Plant Disease, 67(9), 970-973.

Shearer, B., Crane, C., \& Cochrane, A. (2004). Quantification of the susceptibility of the native flora of the south-west botanical province, western australia, to phytophthora cinnamomi. Australian Journal of Botany, 52(4), 435-443.

Shearer, B., Shea, S., \& Deegan, P. (1987). Temperature-growth relationships of phytophthora cinnamomi in the secondary phloem of roots of banksia grandis and eucalyptus marginata. Phytopathology, $77(5), 661-665$.

Shogren, A. J., Tank, J. L., Andruszkiewicz, E., Olds, B., Mahon, A. R., Jerde, C. L., \& Bolster, D. (2017). Controls on edna movement in streams: Transport, retention, and resuspension. Scientific Reports, 7(1), 1-11.

Silva, J. S., \& Rego, F. C. (2003). Root distribution of a mediterranean shrubland in portugal. Plant and Soil, 255(2), 529-540.

Suleman, P., Al-Musallam, A., \& Menezes, C. A. (2001). The effect of solute potential and water stress on black scorch caused by chalara paradoxa and chalara radicicola on date palms. Plant disease, $85(1), 80-83$.

Tarboton, D. (1997). A new method for the determination of flow directions and upslope areas in grid digital elevation models. Water Resources Research, 33(2), 309-319.

Thompson, S. E., Harman, C., Heine, P., \& Katul, G. (2010). Vegetation-infiltration relationships across climatic and soil type gradients. Journal of Geophysical Research: Biogeosciences, 115(G2). 
Thompson, S. E., Levin, S., \& Rodriguez-Iturbe, I. (2013). Linking plant disease risk and precipitation drivers: A dynamical systems framework. The American Naturalist, 181(1), E1-E16.

Thompson, S. E., Levin, S., \& Rodriguez-Iturbe, I. (2014). Rainfall and temperatures changes have confounding impacts on phytophthora cinnamomi occurrence risk in the southwestern usa under climate change scenarios. Global change biology, 20(4), 1299-1312.

Thomson, S., \& Allen, R. (1974). Occurrence of phytophthora species and other potential plant pathogens in recycled irrigation water. Plant Disease Reporter, 58(10), 945-949.

Van Wijk, M. T., \& Rodriguez-Iturbe, I. (2002). Tree-grass competition in space and time: Insights from a simple cellular automata model based on ecohydrological dynamics. Water Resources Research, $38(9), 18-1$.

Vettraino, A., Morel, O., Perlerou, C., Robin, C., Diamandis, S., \& Vannini, A. (2005). Occurrence and distribution of phytophthora species in european chestnut stands, and their association with ink disease and crown decline. European Journal of Plant Pathology, 111(2), 169.

Weste, G., \& Law, C. (1973). The invasion of native forest by phytophthora cinnamomi. iii. threat to the national park, wilson's promontory, victoria. Australian Journal of Botany, 21(1), 31-51.

Weste, G., Ruppin, P., \& Vithanage, K. (1976). Phytophthora cinnamomi in the brisbane ranges: Patterns of disease extension. Australian Journal of Botany, 24(2), 201-208.

Weste, G., \& Taylor, P. (1971). The invasion of native forest by phytophthora cinnamomi. i. brisbane ranges, victoria. Australian Journal of Botany, 19(3), 281-294.

Wilson, B. A., Zdunic, K., Kinloch, J., \& Behn, G. (2012). Use of remote sensing to map occurrence and spread of phytophthora cinnamomi in banksia woodlands on the gnangara groundwater system, western australia. Australian Journal of Botany, 60(6), 495-505.

Xu, C., Silberstein, R., \& Barr, A. (2003). Estimates of groundwater recharge beneath banksia woodland on the swan coastal plain using a vertical flux model (waves): Sensitivity analysis, In Modsim 2003 proceedings of international congress on modelling and simulation. international modelling and simulation society, townsville, queensland.

Zdunic, K., Kinloch, J., Wilson, B., \& Valentine, L. (2010). Mapping the extent and rate of spread of phytophthora cinnamomi in banksia woodlands on the gnangara groundwater system. Department of Environment; Conservation; Gnangara Sustainability Strategy.

\section{Figure Captions}

- Table 1: Evidence of transport of Pc via surface water.

- Figure 1: Distinct pathogen spread patterns observed at the site in Western Australia (A) and the site in Spain (B). Topographic contours are shown in 5 meter increments. 
- Figure 2: During each time step, the water balance for the soil is computed (A) with precipitation as the input and evapotranspiration $(\mathrm{ET})$, percolation $(\mathrm{L})$, and overland flow $\left(\mathrm{q}_{\text {storm }}\right)$ as outputs. In the event of overland flow generation, the routing of runoff between source (i) and sink (j) cells along flowpaths $(\ell)$ and the resulting advective transport is calculated in the overland transport portion of the model (B). The soil moisture and temperature from the water balance and environmental conditions are used to parameterize the growth rate and diffusion coefficient $(\mathrm{C})$ which, along with any input from overland transport, determine the change in biomass density in each cell. With these changes in biomass density, the Pc biomass density field is output at the end of each time step (D). This is then further binarized to presence or absence of Pc infection, where cells with biomass density at least $0.5 B_{\max }$ categorized as infected.

- Figure 3: In the flow routing portion of the model (A), the D- $\infty$ algorithm (Tarboton, 1997) is used to determine the flow between a source cell (i) with upslope area $\mathrm{A}_{i}$ and a downslope sink cell (j). In the algorithm, flow is assumed to travel in the direction of the steepest downhill descent. When this results in flow being split between two adjacent cells, the relative fraction to each cell $(\phi)$ is determined by the angles as shown in (A). For each sink cell, the contributions of each upslope source cell are treated individually, with the final cumulative deposited biomass $\left(M_{j}^{+}\right)$coming from the superposition of all the upslope sources (B).

- Table 2: Variables and parameters used across all components of the model.

- Figure 4: Schematic demonstrating how the different versions of the model are compared to one another and the conclusions (denoted with boxes) that can be drawn from the different potential outcomes

- Figure 5: (A) PDF of modeled soil moisture (in blue) at the site in Western Australia as compared to soil moisture measurements made to a depth of $160 \mathrm{~cm}$ at the Gingin OzFlux site (gray) in 2015. (B) PDFs of modeled soil moisture values for the Spanish site for the 1981-1984 (light blue) and 2010-2012 (dark blue) study periods. (C) Comparison of Soil Moisture Active Passive (SMAP) surface layer estimates (gray) for the Spain site from 2018 as compared to modeled values over both study periods (blue) with the summer period (June through September) removed for both sets. Because of differences in the assumptions of maximum and minimum values of soil moisture in the data from Gingin and SMAP, both are scaled to the maximum and minimum soil moisture values for the respective sites in the model so as to better enable comparison of the soil moisture dynamics.

- Figure 6: Model output from the Western Australia site for Patch b (A) and Patch h (B), with observed initial and final patch extents outlined and model predictions shaded. Model predictions 
for the different model configurations tested at the Spanish site are shown for Patch 7 (C) and Patch 2 (D). Composite scores of all patches for the model configuration allowing for overland transport are shown for both sites in (E), with the Spanish patches subset into patches that varied greatly between configurations (red dots) and those that had minimal variation (blue dots). For the Spanish site, the improvements in composite scores for each patch with adding overland transport relative to the other configurations are shown in $(\mathrm{F})$, with the color scheme continued from $(\mathrm{E})$.

- Table 3: Tuned values for pathogen mortality rate $(d)$, pathogen growth rate temperature dependence $(\Delta r)$, and maximum pathogen diffusion coefficient $\left(D_{\max }\right)$ for different tested configurations at both sites. For the Western Australia site, no overland flow occurred so there was no differentiation between the "Diffusion" Optimized and Overland Transport model configurations.

- Figure 7: A comparison of the observed rate of growth in patch area at the Spanish site and the rate predicted by both including overland transport in the prediction and with overland transport turned off. Model prediction areal growth rate values only include the growth area which was correctly predicted by the model, in other words, false positives were excluded. 
Figures 


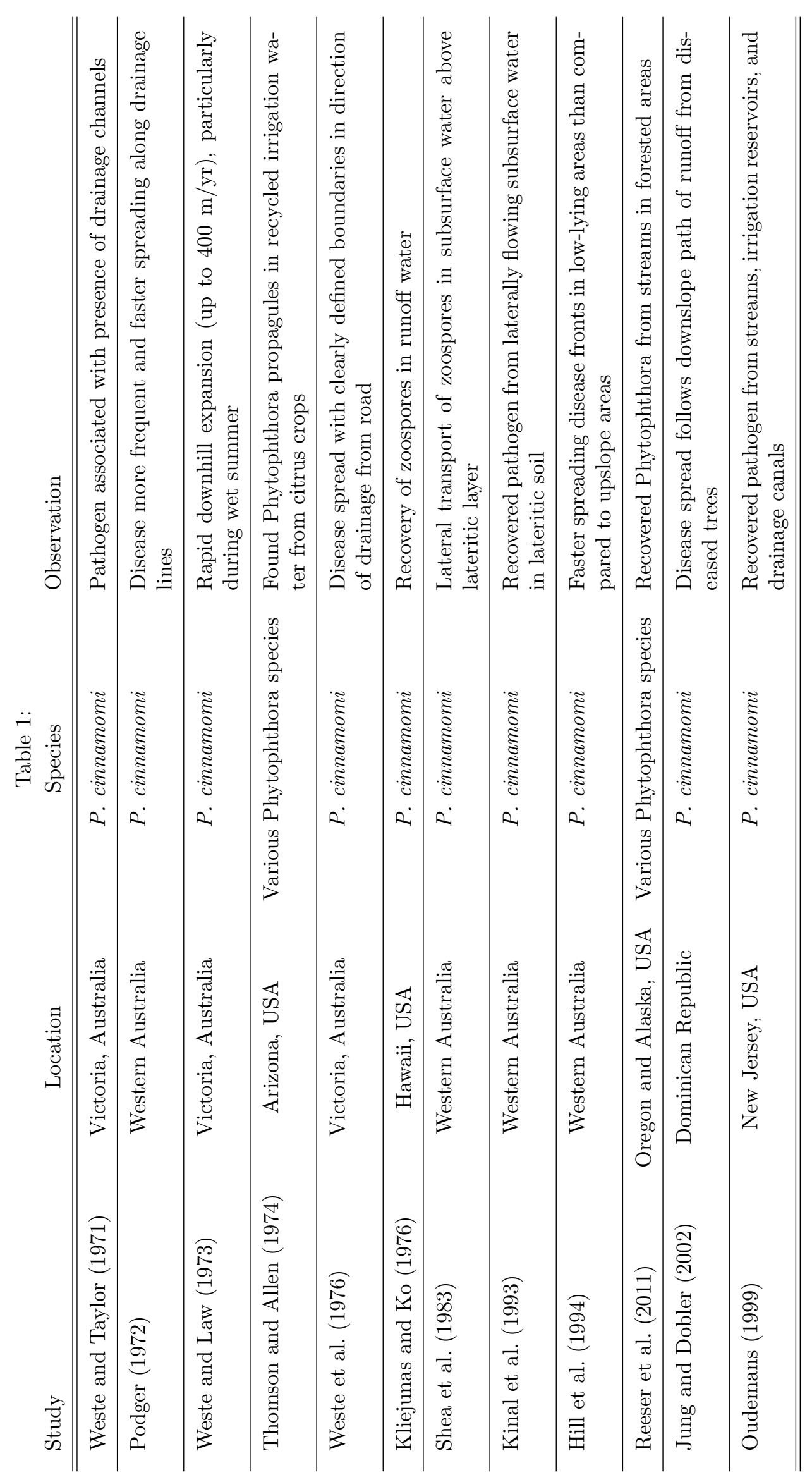


A) Western Australia
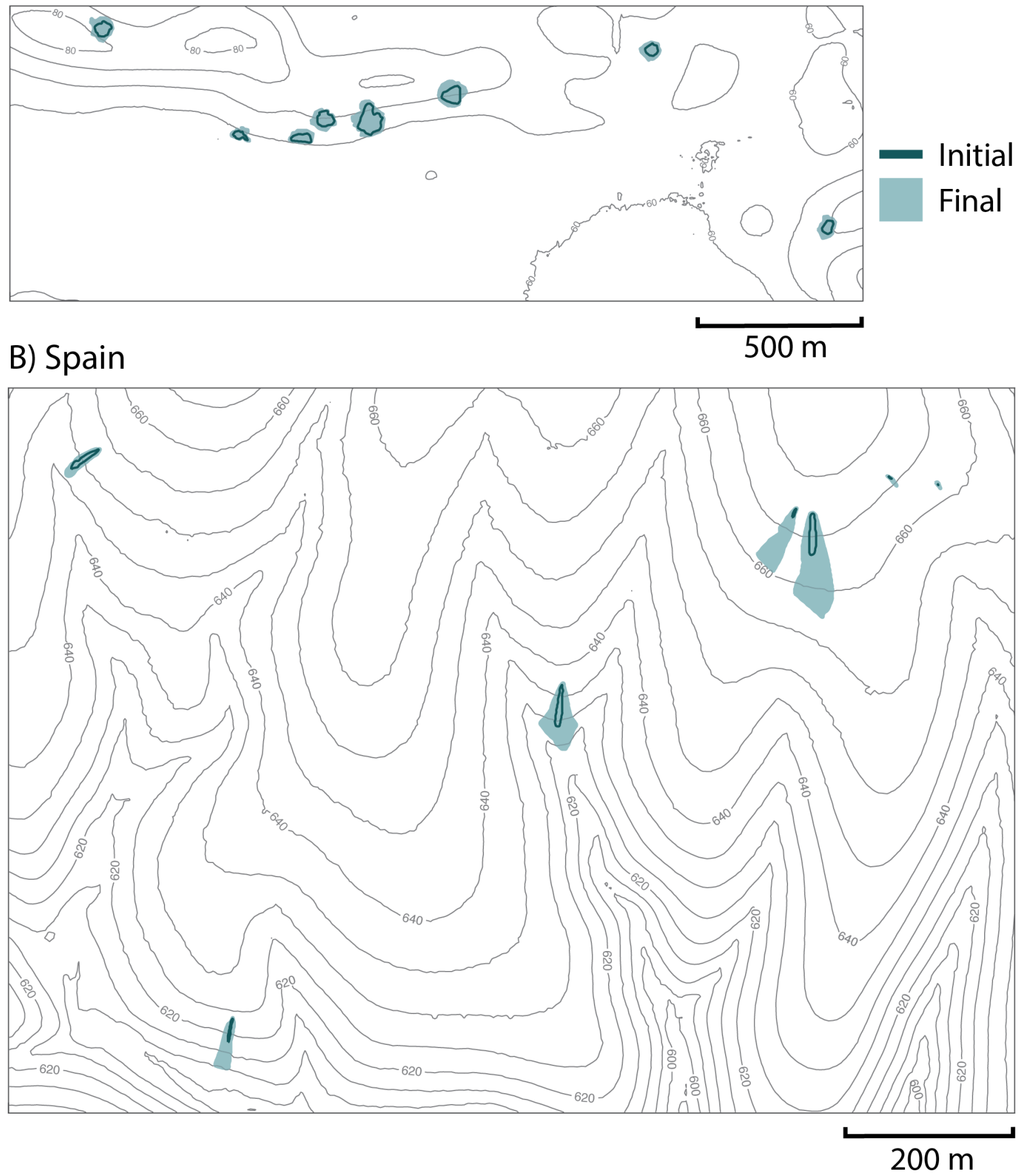

Figure 1: 

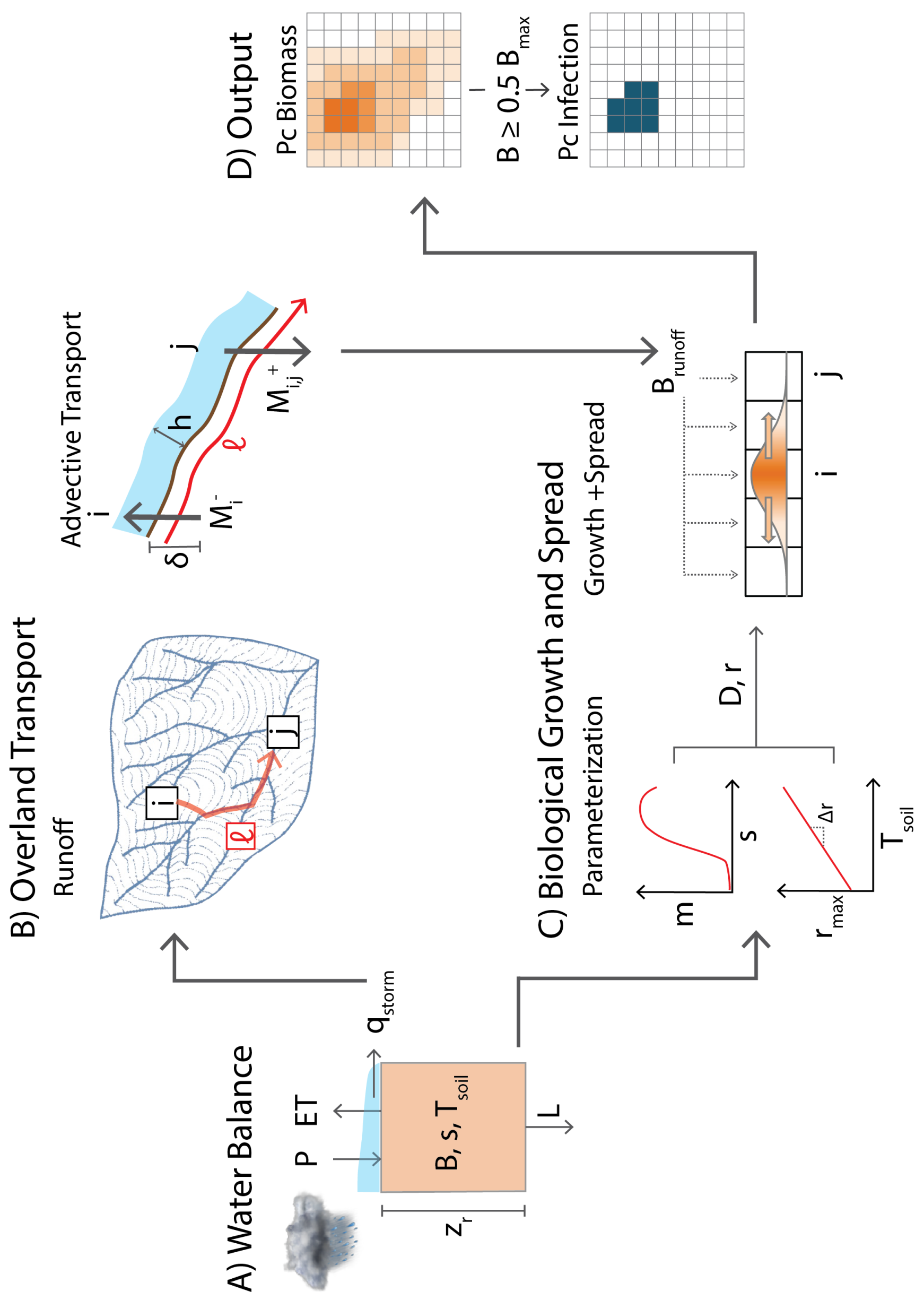
A) Routing on topographic grid

D- $\infty$ algorithm
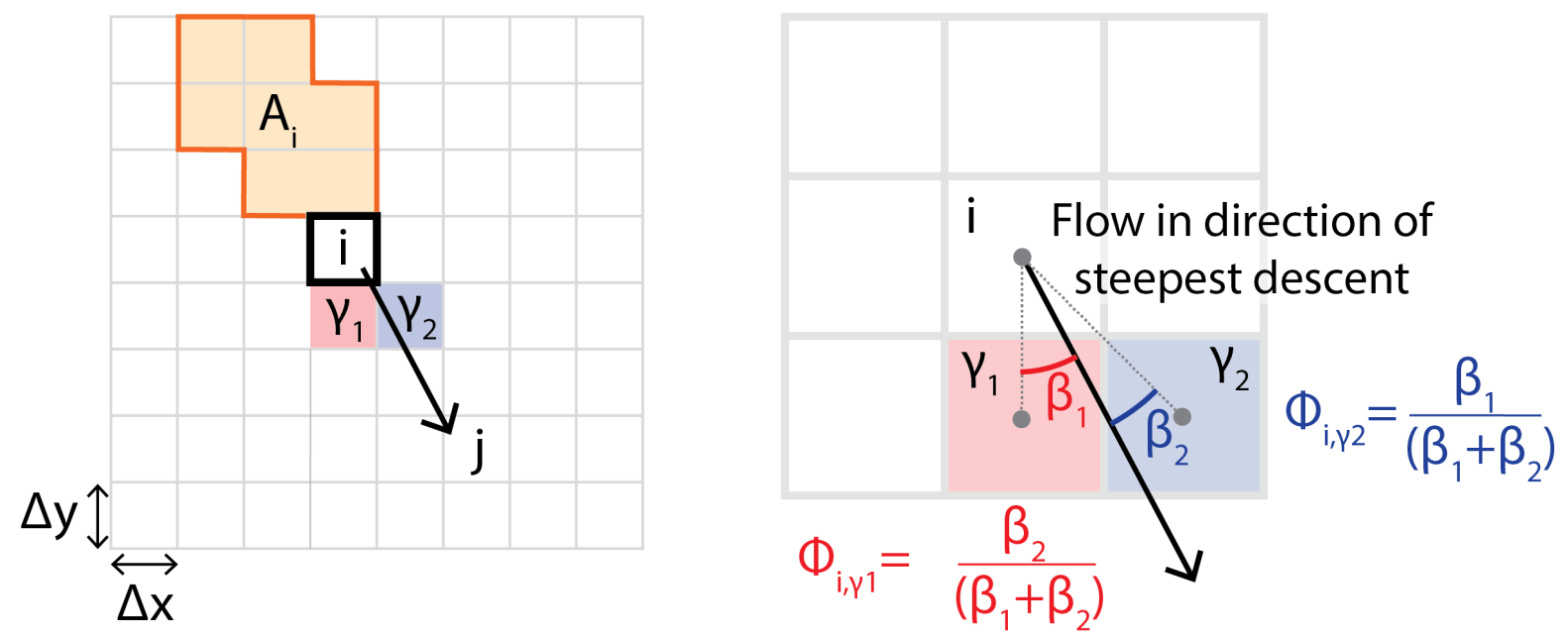

B) Superposition of concentrations and sink fluxes at Cell j

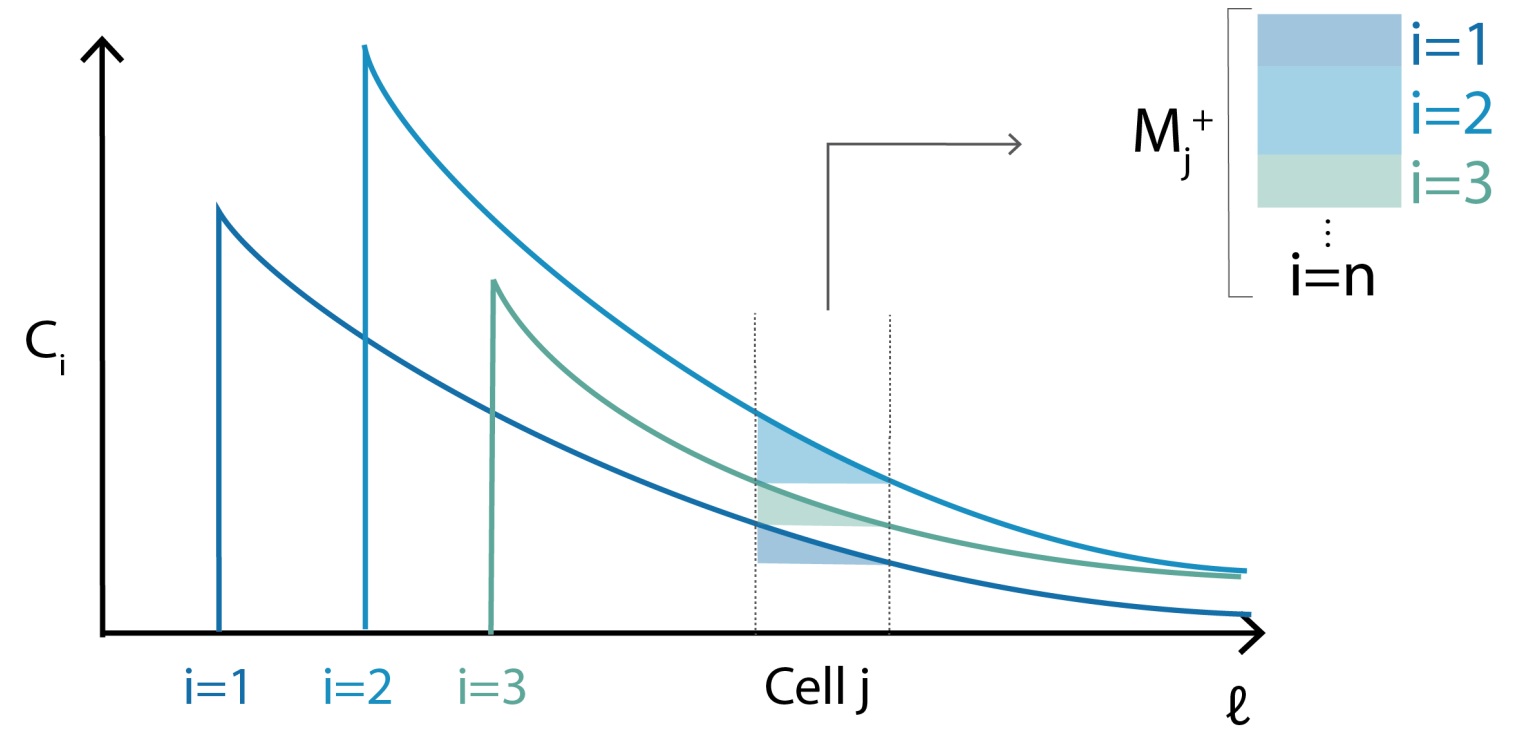

Figure 3: 


\begin{tabular}{|c|c|c|c|}
\hline Symbol & Description & Dimensions & Units \\
\hline \multicolumn{4}{|c|}{ Discretization } \\
\hline$\Delta t$ & Time step & $\mathrm{T}$ & day \\
\hline$\Delta x, \Delta y$ & Spatial step & $\mathrm{L}$ & $\mathrm{m}$ \\
\hline \multicolumn{4}{|c|}{ Soil moisture balance } \\
\hline$z_{r}$ & Soil vertical domain & $\mathrm{L}$ & $\mathrm{mm}$ \\
\hline$s$ & Mean relative soil water content & - & - \\
\hline$V_{\text {water }}$ & Volume soil water per unit area & $\mathrm{L}$ & $\mathrm{mm}$ \\
\hline$n$ & Soil porosity & - & - \\
\hline$f$ & Rate of infiltration & $\mathrm{L} \mathrm{T}^{-1}$ & $m m$ day $^{-1}$ \\
\hline$g$ & Rate of evapotranspiration & $\mathrm{L} \mathrm{T}^{-1}$ & $m m$ day $^{-1}$ \\
\hline$K_{\text {sat }}$ & Soil saturated hydraulic conductivity & $\mathrm{L} \mathrm{T}^{-1}$ & $m m$ day $^{-1}$ \\
\hline$q$ & Surface flow rate & $\mathrm{L} \mathrm{T}^{-1}$ & $m m$ day $^{-1}$ \\
\hline$t_{\text {storm }}$ & Length of storm event & $\mathrm{T}$ & day \\
\hline$s_{w p}$ & Soil moisture wilting point & - & - \\
\hline$s^{*}$ & Soil moisture point of full stomatal opening & - & - \\
\hline$E T_{\max }$ & Maximum evapotranspiration rate & $\mathrm{L} \mathrm{T}^{-1}$ & $m m$ day $^{-1}$ \\
\hline$P$ & Precipitation rate & $\mathrm{L} \mathrm{T}^{-1}$ & $m m$ day $^{-1}$ \\
\hline$q_{\text {storm }}$ & Average rate of flow production for storm event & $\mathrm{L} \mathrm{T}^{-1}$ & $m m$ day $^{-1}$ \\
\hline$L$ & Rate of percolation at bottom boundary & $\mathrm{L} \mathrm{T}^{-1}$ & $m m$ day $^{-1}$ \\
\hline$b$ & Soil-water retention curve exponent & - & - \\
\hline \multicolumn{4}{|c|}{ Runoff routing and propagule transport } \\
\hline$\phi_{i, j}$ & Fraction of overland flow from cell $i$ to downslope cell $j$ & - & - \\
\hline$A_{i}$ & Upslope contributing area to $i$ & $\mathrm{~L}^{2}$ & $\mathrm{~m}^{2}$ \\
\hline$B$ & Biomass density per area & $\mathrm{M} \mathrm{L}^{-2}$ & $\mathrm{~g} \mathrm{~m}^{-2}$ \\
\hline$\delta$ & Effective soil depth of interaction with overland flow & $\mathrm{L}$ & $\mathrm{mm}$ \\
\hline$\chi_{i j}$ & Euclidean distance between cells $i$ and $j$ & $\mathrm{~L}$ & $\mathrm{~m}$ \\
\hline$B_{\text {runoff }}$ & Net change in biomass density as a result of overland flow & $\mathrm{M} \mathrm{L}^{-2}$ & $\mathrm{~g} \mathrm{~m}^{-2}$ \\
\hline$h$ & Depth of overland flow & $\mathrm{L}$ & $\mathrm{m}$ \\
\hline$C$ & Concentration of biomass in runoff & $\mathrm{M} \mathrm{L}^{-3}$ & $\mathrm{~g} \mathrm{~m}^{-3}$ \\
\hline$q_{c}$ & Water flux per unit width channel & $\mathrm{L}^{2} \mathrm{~T}^{-1}$ & $m^{2}$ day $^{-1}$ \\
\hline$\alpha$ & Tunable overland transport parameter & $\mathrm{L}^{-\frac{1}{5}} \mathrm{~T}^{-\frac{2}{5}}$ & $\mathrm{~m}^{-\frac{1}{5}} \mathrm{day}^{-\frac{2}{5}}$ \\
\hline$\overline{u_{i, j}}$ & Mean runoff velocity between $i$ and $j$ & $\mathrm{~L} \mathrm{~T}^{-1}$ & $m$ day $^{-1}$ \\
\hline$C_{i o}$ & Concentration of biomass in runoff at source cell & $\mathrm{M} \mathrm{L}^{-3}$ & $\mathrm{~g} \mathrm{~m}^{-3}$ \\
\hline$M_{i j}^{+}$ & Deposited biomass at cell $j$ originating from $i$ & M & $\mathrm{g}$ \\
\hline$M_{j}^{+}$ & Total deposited biomass at cell $j$ & M & $\mathrm{g}$ \\
\hline$u^{J}$ & Runoff velocity & $\mathrm{L} \mathrm{T}^{-1}$ & $m$ day $^{-1}$ \\
\hline$K$ & Kinematic resistance factor & $\mathrm{L}^{\frac{1}{3}} \mathrm{~T}^{-1}$ & $m^{\frac{1}{3}}$ day $^{-1}$ \\
\hline$\nu$ & Land surface flow resistance & $\mathrm{L}^{\frac{-1}{3}} \mathrm{~T}$ & $m^{\frac{-1}{3}}$ day \\
\hline$M_{i}^{-}$ & Biomass mobilized from cell $i$ & M & $\mathrm{g}$ \\
\hline$\gamma_{i}$ & Fraction of mobilized biomass from $i$ deposited in domain & - & - \\
\hline$\ell$ & Overland flow path coordinate & $\mathrm{L}$ & $\mathrm{m}$ \\
\hline$\beta$ & Sink strength rate parameter & $\mathrm{T}^{-1}$ & day $^{-1}$ \\
\hline $\bar{h}$ & Spatially-averaged runoff depth & $\mathrm{L}$ & $\mathrm{m}$ \\
\hline$v$ & Aggregated velocity factor & $\mathrm{L}^{\frac{4}{5}} \mathrm{~T}^{-\frac{2}{5}}$ & $m^{\frac{4}{5}}$ day $^{-\frac{2}{5}}$ \\
\hline$\overline{v_{i, j}}$ & Spatially-averaged aggregated velocity factor & $\mathrm{L}^{\frac{4}{5}} \mathrm{~T}^{-\frac{2}{5}}$ & $m^{\frac{4}{5}}$ day $^{-\frac{2}{5}}$ \\
\hline$\Delta \ell$ & Flow path length within cell & L & $\mathrm{m}$ \\
\hline$\overline{u_{j}}$ & Storm-averaged runoff velocity at $j$ & $\mathrm{~L} \mathrm{~T}^{-1}$ & $m$ day $^{-1}$ \\
\hline \multicolumn{4}{|c|}{ Pathogen growth and diffusive spread } \\
\hline$r_{\max }$ & Maximum fractional growth rate at ambient temperature & - & - \\
\hline$T_{\text {soil }}$ & Soil temperature & $\mathrm{K}$ & ${ }^{\circ} \mathrm{C}$ \\
\hline$m$ & Pathogen growth soil moisture dependence factor & - & - \\
\hline$r_{o}$ & Pathogen fractional growth rate at $\mathrm{T}=0^{\circ} \mathrm{C}$ & - & - \\
\hline$\Delta r$ & Pathogen growth rate temperature dependence & $K^{-1}$ & ${ }^{\circ} \mathrm{C}^{-1}$ \\
\hline$d$ & Mortality rate & - & - \\
\hline$B_{\max }$ & Steady state pathogen biomass density & $\mathrm{M} \mathrm{L}^{-2}$ & $\mathrm{~g} \mathrm{~m}^{-2}$ \\
\hline$D_{\max }$ & Maximum pathogen diffusion coefficient & $\mathrm{L}^{2} \mathrm{~T}^{-1}$ & $\mathrm{~m}^{2}$ day $^{-1}$ \\
\hline
\end{tabular}

Table 2: 


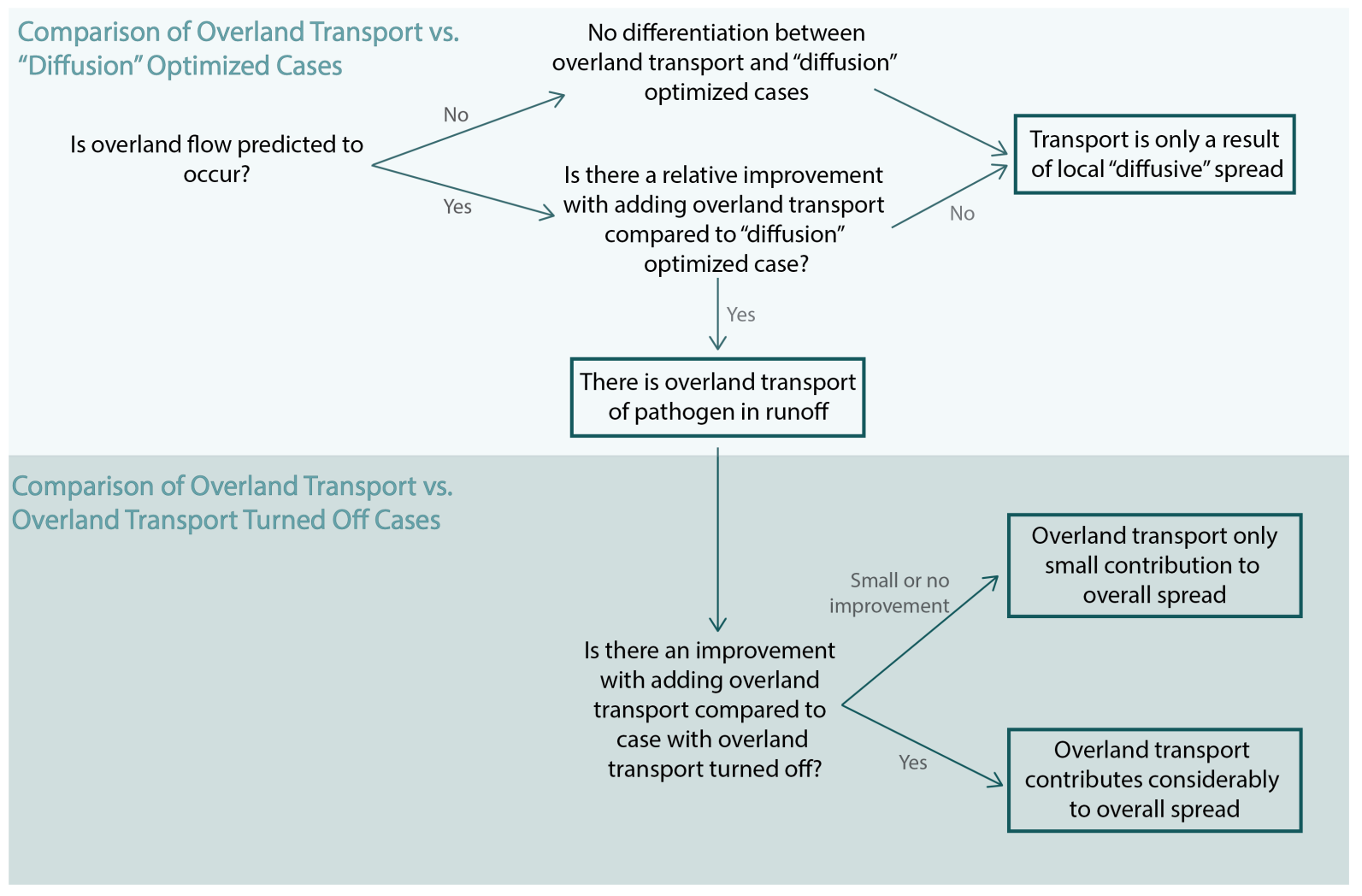

Figure 4: 

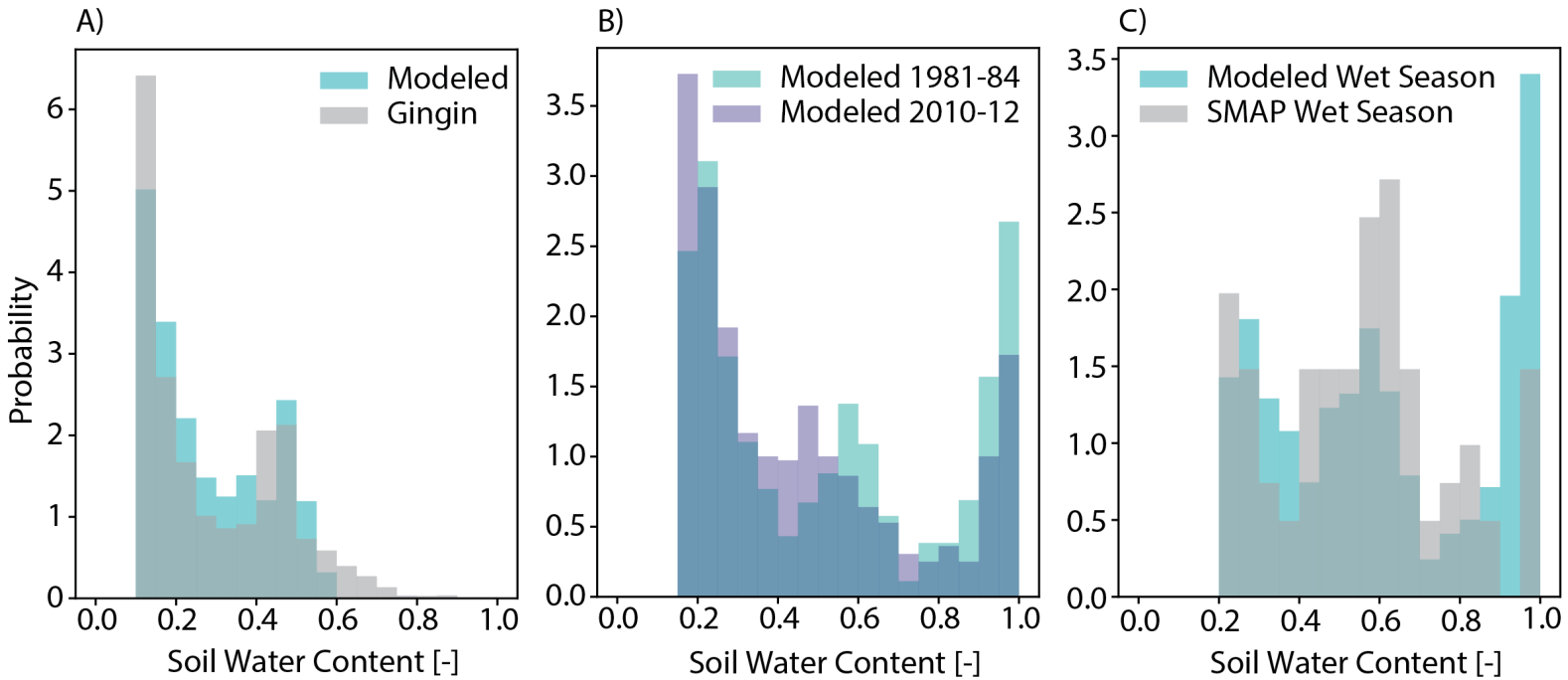

Figure 5: 
Initial
Final
Predicted

A)

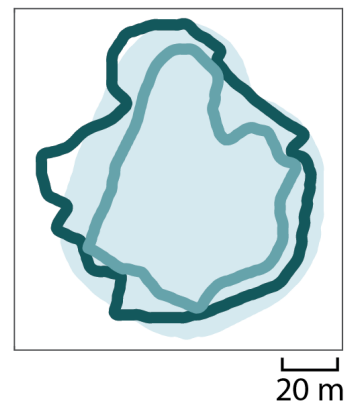

B)

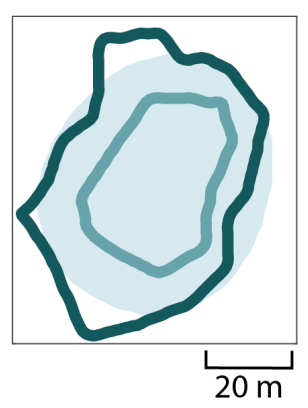

E)

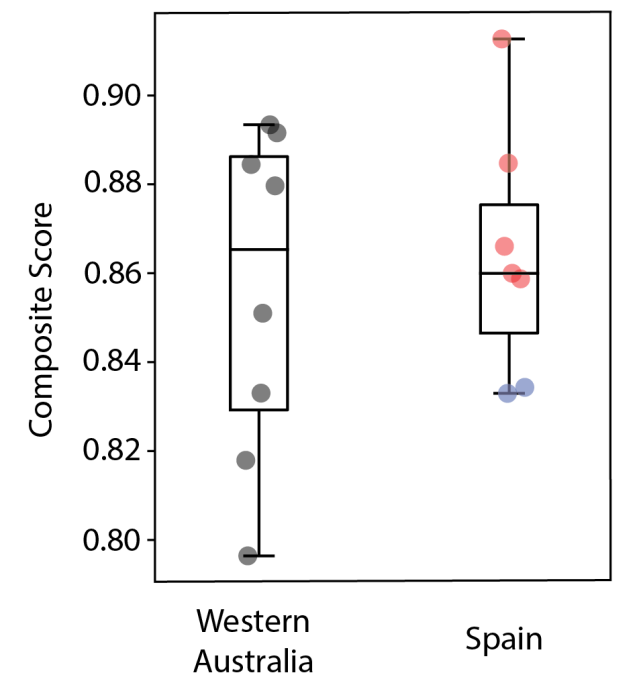

C) Overland Transport

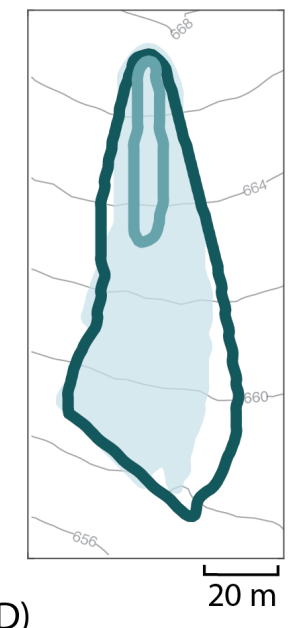

D)

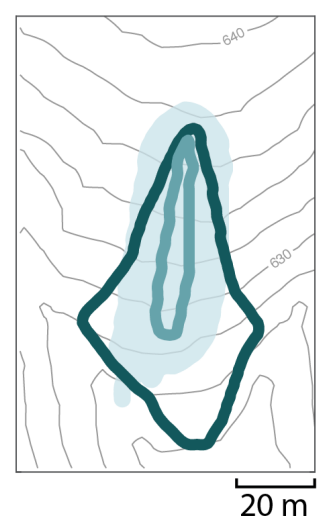

"Diffusion" Optimized
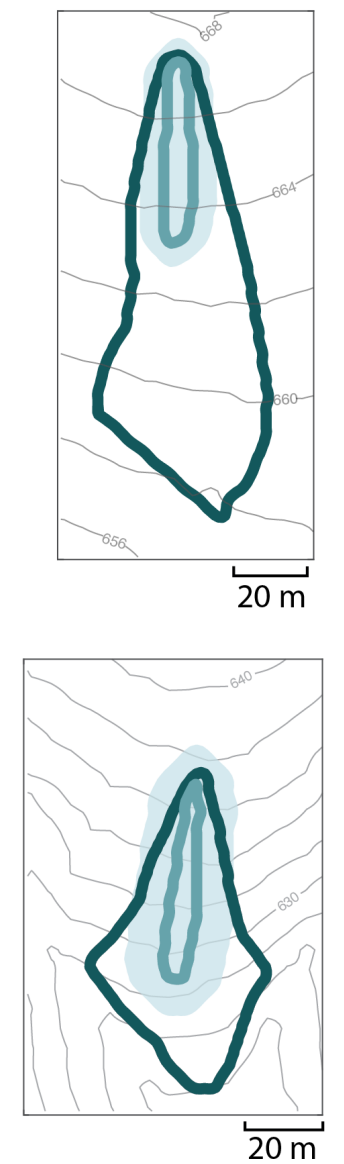

Overland Transport Turned Off
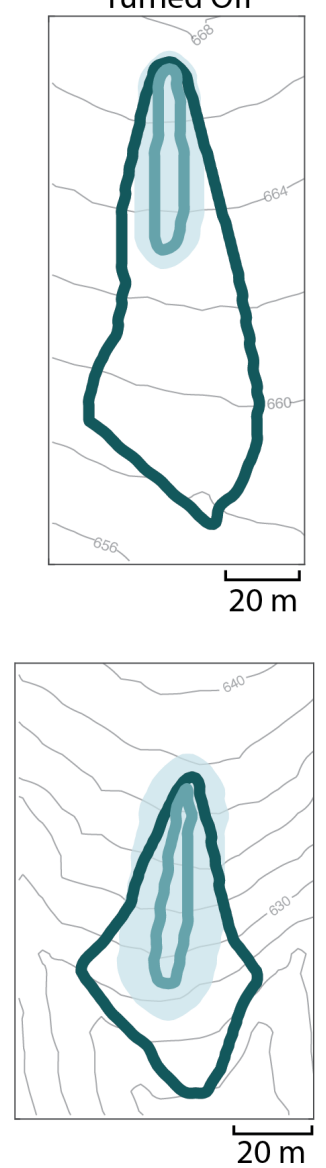

F)

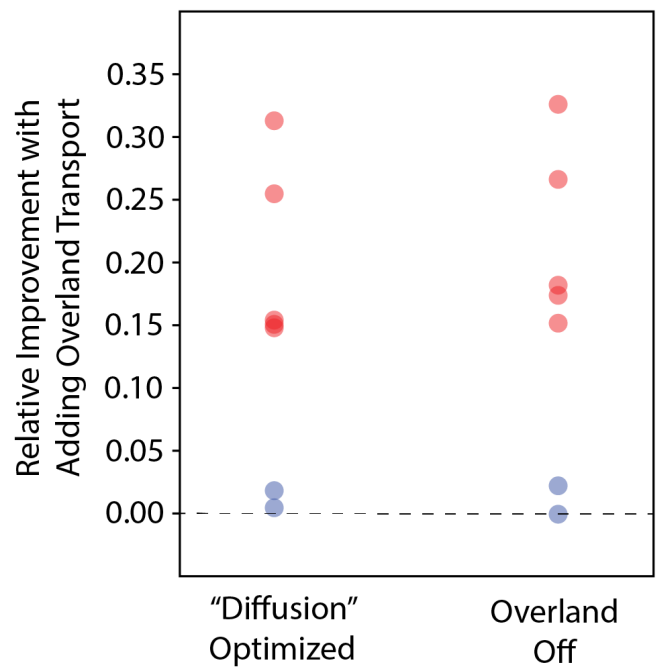

Figure 6: 


\begin{tabular}{l|l|l|l|l} 
Site & Configuration & $d[-]$ & $\Delta r\left[{ }^{\circ} \mathrm{C}^{-1}\right]$ & $D_{\max }\left[\mathrm{m}^{2} \mathrm{day}^{-1}\right]$ \\
\hline \hline Western Australia & Overland Transport/"Diffusion" Optimized & 0.14 & 0.03 & 0.025 \\
Spain & Overland Transport & 0.12 & 0.04 & 0.0014 \\
Spain & 0.08 & 0.06 & $7.5 \mathrm{e}^{-9}$
\end{tabular}

Table 3: 


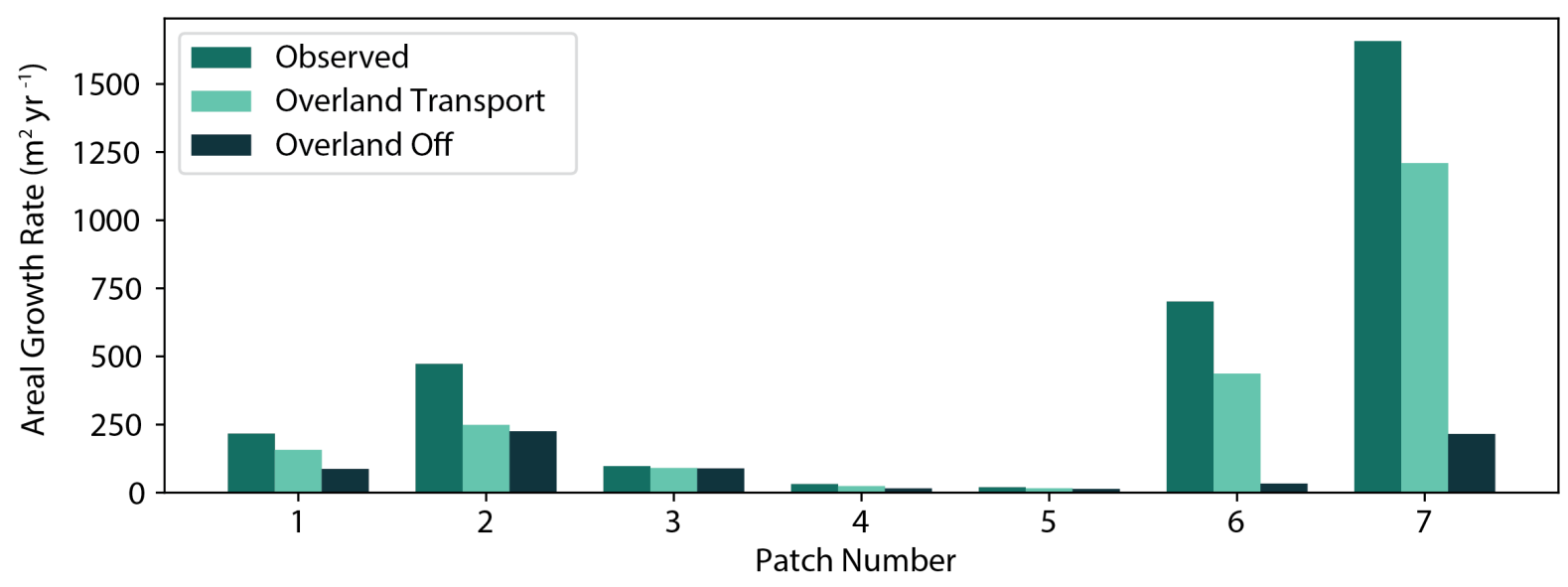

Figure 7: 


\section{Appendices}

$$
\gamma_{i}=\frac{\sum_{j=1}^{n} \frac{e^{\frac{-\alpha \chi_{i, j}}{\bar{v}_{i, j}}} \phi_{i, j}}{v_{j}}}{\sum_{j=1}^{\infty} \frac{e^{\frac{-\alpha \chi_{i, j}}{\bar{v}_{i, j}}} \phi_{i, j}}{v_{j}}}
$$

\section{A Conservation of Pathogen Mass with Flow Outside Model Domain}

To account for possible transport outside the domain, the fraction of biomass accounted for within the domain that originated at $i, \gamma_{i}$, is found:

where $n$ is the number of down-gradient cells within the modeled domain. For the theoretical limit of $\infty$ down-gradient cells, the sum is computed using $\Delta x$ as the increment in distance between the cells $\left(\chi_{i, j}\right)$ and the velocities, $v_{j}$ and $\overline{v_{i, j}}$, are approximated using the respective averages of those values within the modeled domain. This sum is computed until the incremental change in the sum with each additional term falls below a prescribed threshold value (set to 0.00001 in this case). This value can then be used in the calculation of $C_{i o}$ as derived in the main text:

$$
C_{i o}=\frac{B_{i} \delta \Delta x \Delta y}{z_{r}}\left(\sum_{j=1}^{n} \frac{\alpha e^{\frac{-\alpha \chi_{i, j}}{\bar{v}_{i, j}}} \Delta x q_{\text {storm }} A_{i} \phi_{i, j} t_{\text {storm }}}{v_{j}}\right)^{-1}
$$

\section{B Moisture Dependence of Growth}




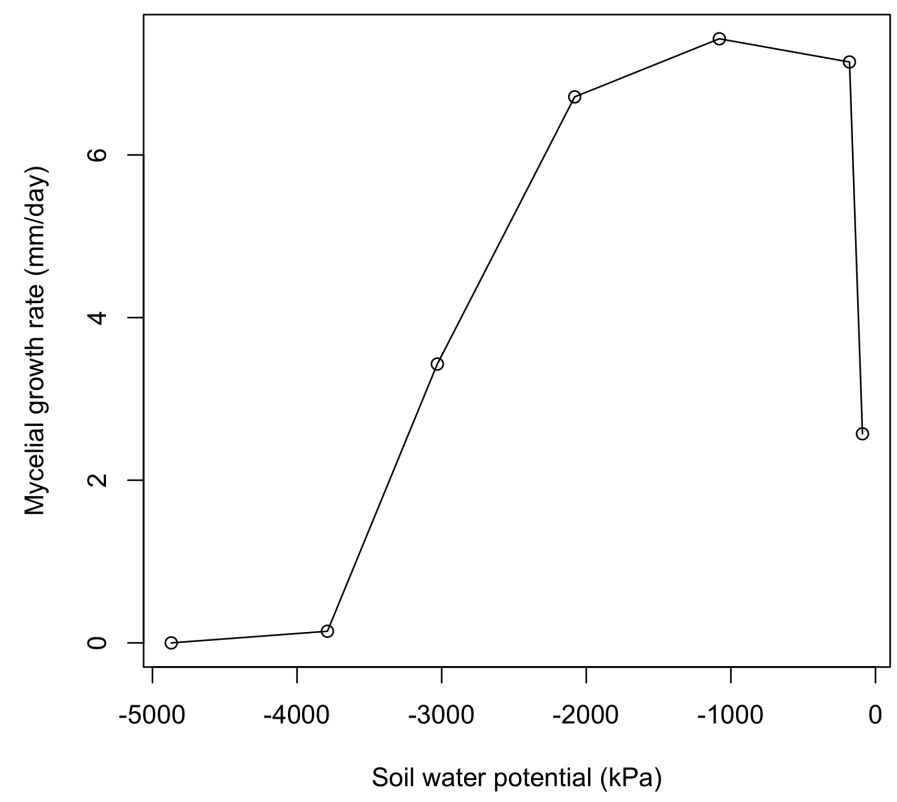

Figure B.1: A piecewise function of the moisture-dependence of pathogen growth $[m(s)]$ was found by linearly fitting segments to the data of Malajczuk and Theodorou, 1979

\section{Patch Image Analysis}

Using the image analysis tools in Matlab, an ellipse is fit to the infected cells $\left(B \geq 0.5 B_{\max }\right)$ such that the ellipse has the same normalized second moment of mass as the disease patch. With this fitted ellipse, the major axis, orientation, and eccentricity are then calculated.

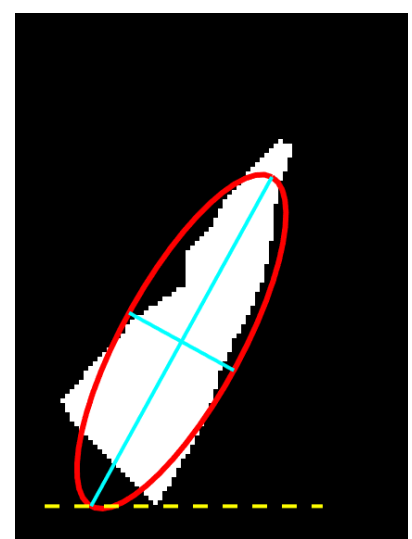

Figure C.1: For each patch of diseased cells (shown in white), an ellipse (red) is fitted. The major and minor axes of the ellipse (blue) are then found and further used to calculate the eccentricity. The orientation is determined as the angle between the major axis and the horizontal plane (dotted yellow). 


\section{Calculation of Composite Score}

A composite score that quantifies how each patch prediction compares to the observed patch is calculated as the average of the following four components. The first three component scores use metrics from the ellipse fitting as described in C. For each of the individual components, as well as the overall score, the values range from 0 (poor match to observations) to 1 (perfect match to observations).

\section{Orientation score:}

The orientation (degrees) of the major axis of the fitted ellipses is measured in degrees in the x-y plane. The differences between orientation for model and observations is computed, normalized by the half circle and differenced from one (to ensure that a score that is closer to one represents better model-observation agreement):

$$
O S=1-\frac{\mid \text { Modeled Orientation }- \text { Observed Orientation } \mid}{180}
$$

\section{Major axis score:}

The length of the major axes of the patches are compared and standardized by the observed major axis length, as:

$$
M S=1-\frac{\mid \text { Modeled Major Axis Length }- \text { Observed Major Axis Length } \mid}{\text { Observed Major Axis Length }}
$$

\section{Eccentricity score:}

The eccentricity (-) of the fitted ellipse is calculated as the distance from the center of the ellipse to the focus divided by one-half the major axis length. It will be equal to 0 for a perfect circle and 1 for a line and in terms of the major and minor axis lengths this is:

$$
\text { Eccentricity }=\frac{\sqrt{(0.5 \times \text { major axis })^{2}+(0.5 \times \text { minor axis })^{2}}}{0.5 \times \text { major axis }}
$$

The eccentricities are compared between model and observations, to form a standardized score:

$$
E S=1-\mid \text { Modeled Eccentricity - Observed Eccentricity } \mid
$$

Growth area: The growth score assesses how well the model predicts where new pathogen growth will occur, relative to how much it overpredicts disease spread. The actual observed growth is tabulated as the number of model grid cells where new pathogen growth is observed between the initial and final observation points. The correctly predicted cells are the number of these cells which the model correctly predicts as being infected by Pc. The number of false positives is tabulated as the number of cells for which the model predicted pathogen growth but there was no observed pathogen present in the aerial photos. These are combined to calculate the growth score as: 


$$
G S=\frac{\# \text { cells new growth correctly predicted }}{\# \text { cells actual new growth observed }+ \text { \# cells with false positives }}
$$

\section{${ }_{1013}$ E All Western Australia Patch Predictions}

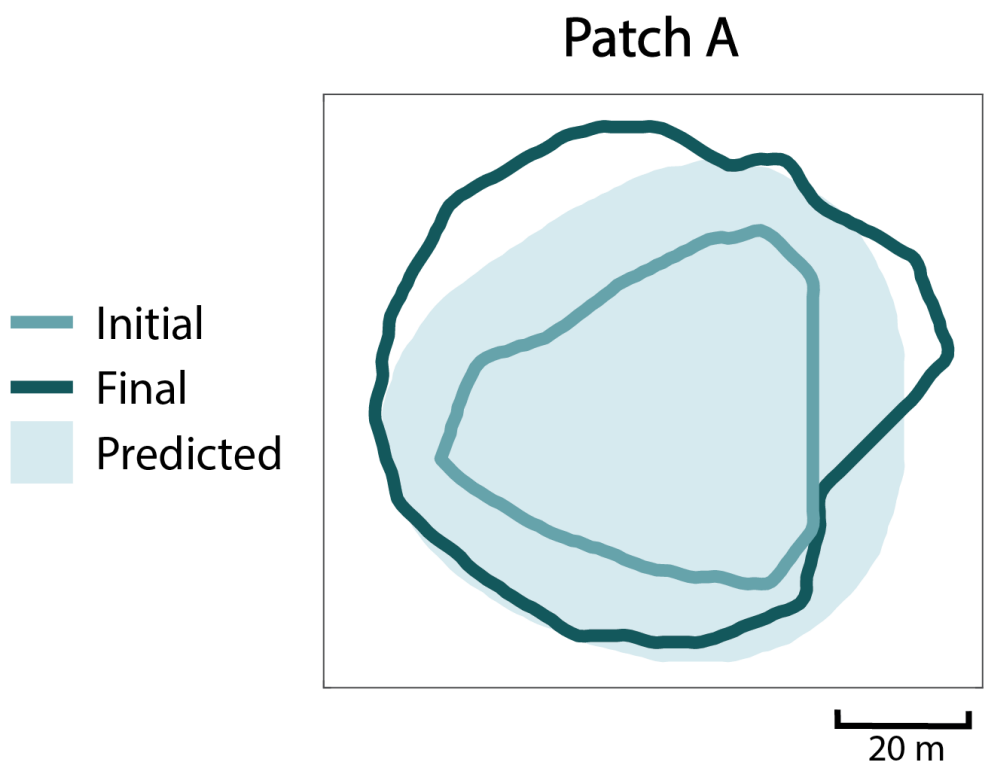

Figure E.1: Composite score of 0.892 


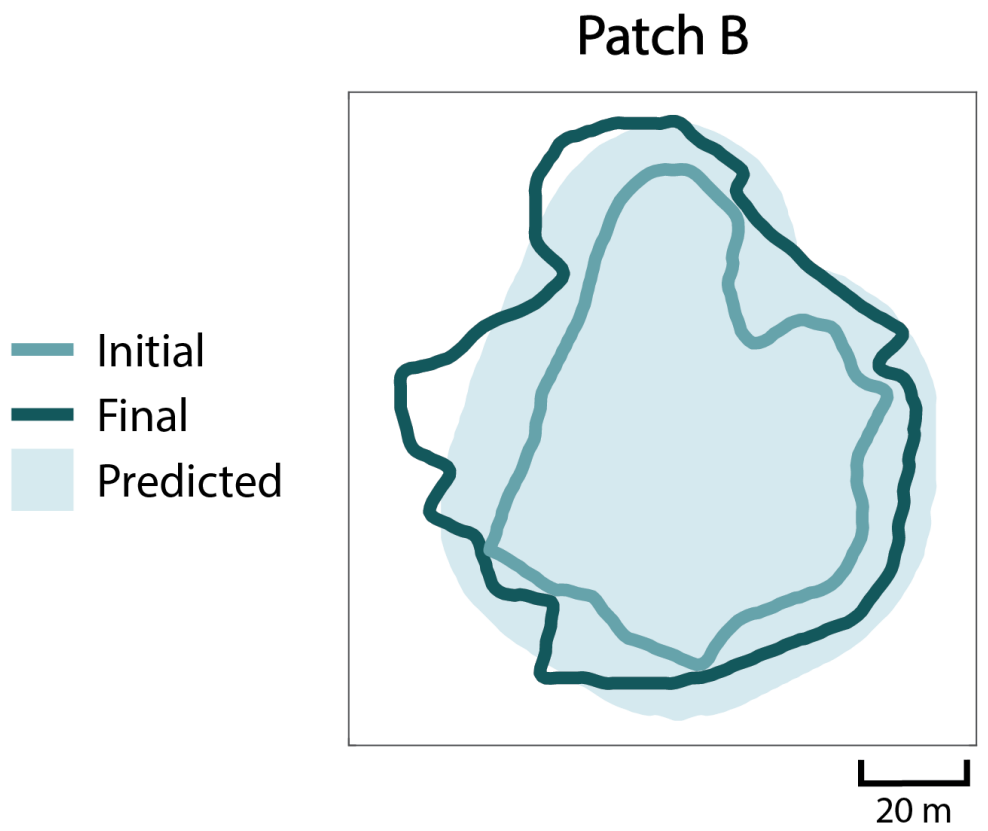

Figure E.2: Composite score of 0.884

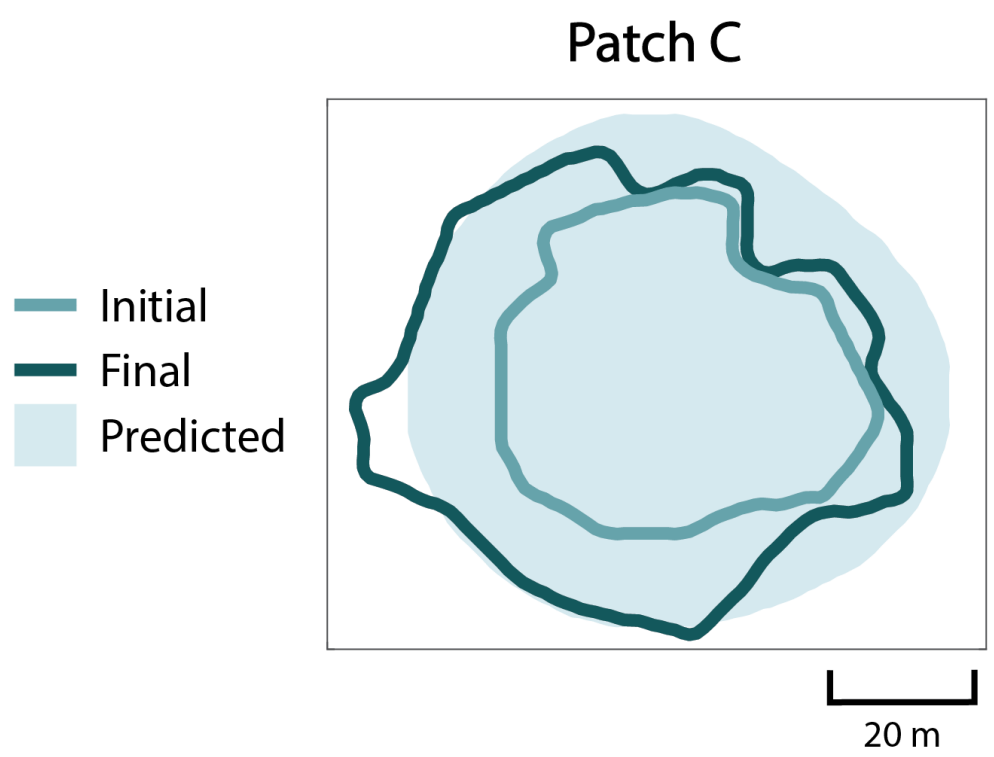

Figure E.3: Composite score of 0.851 


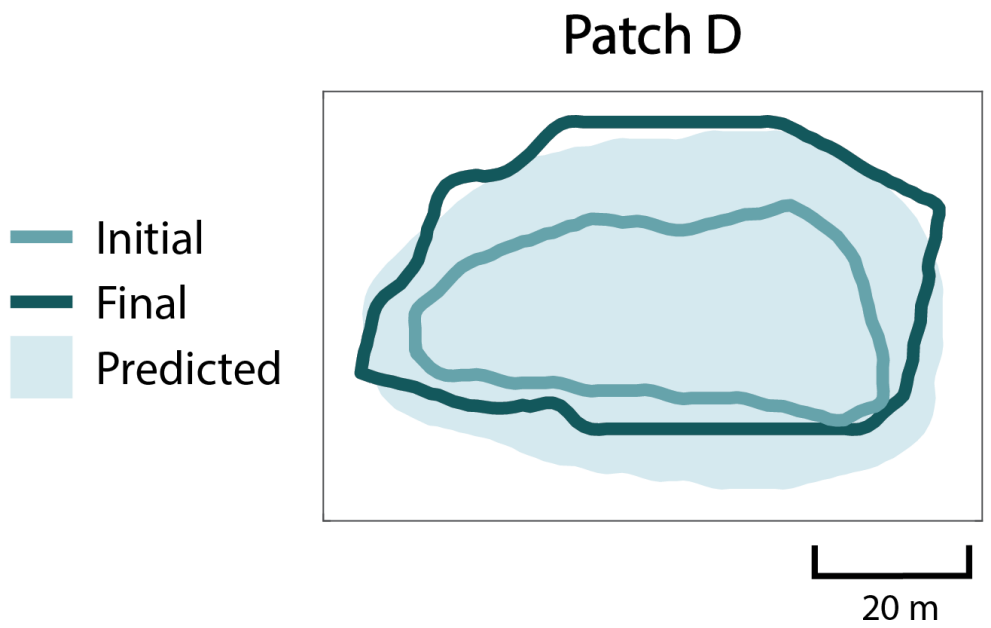

Figure E.4: Composite score of 0.893

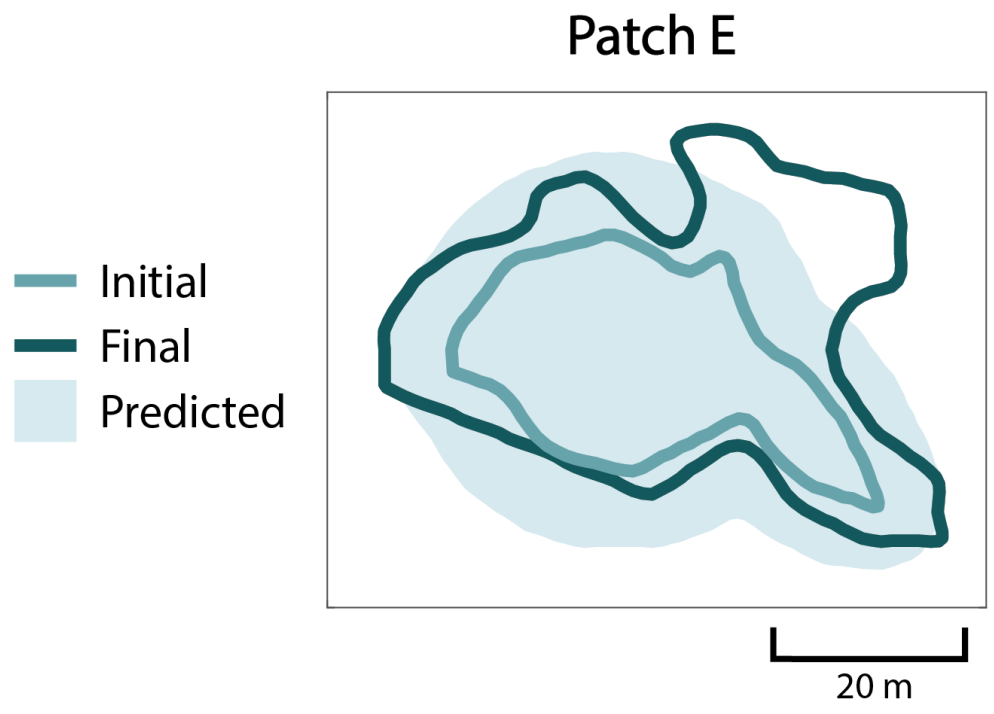

Figure E.5: Composite score of 0.833 


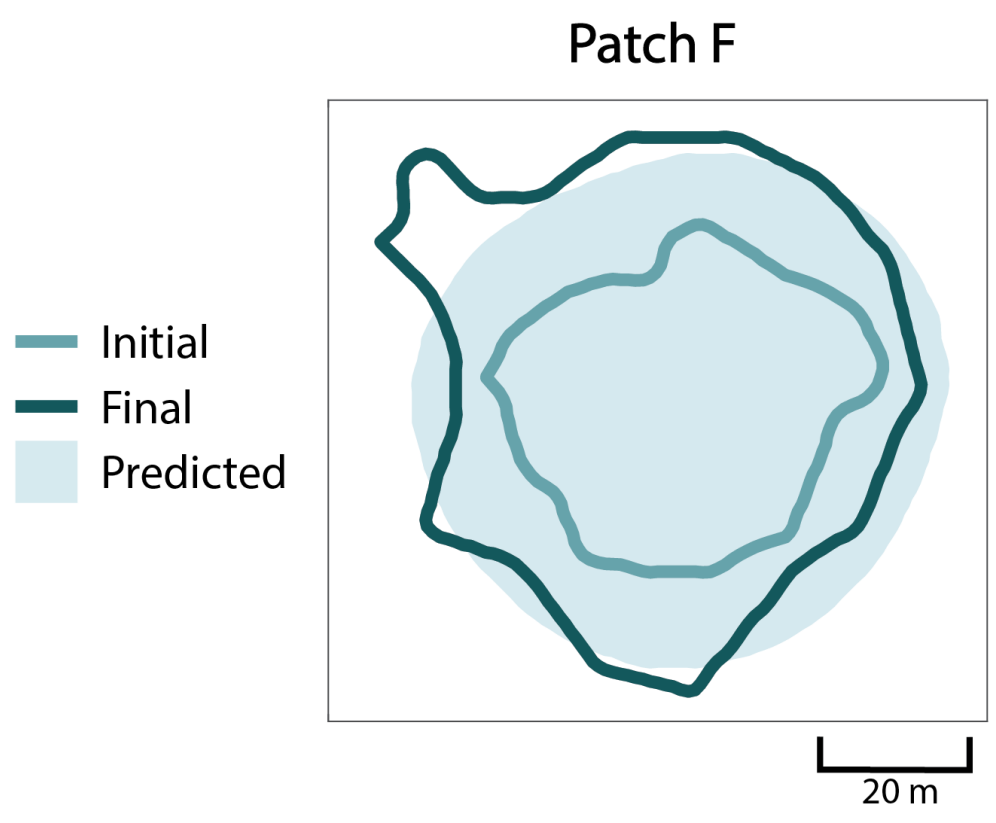

Figure E.6: Composite score of 0.796

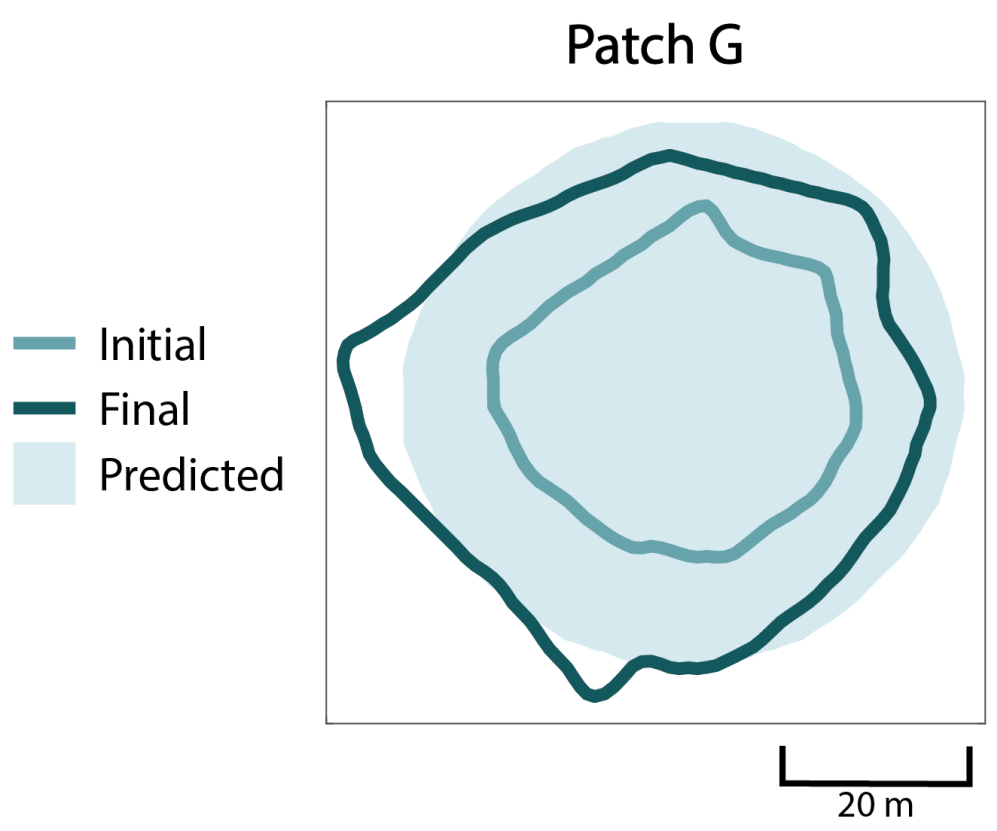

Figure E.7: Composite score of 0.880 


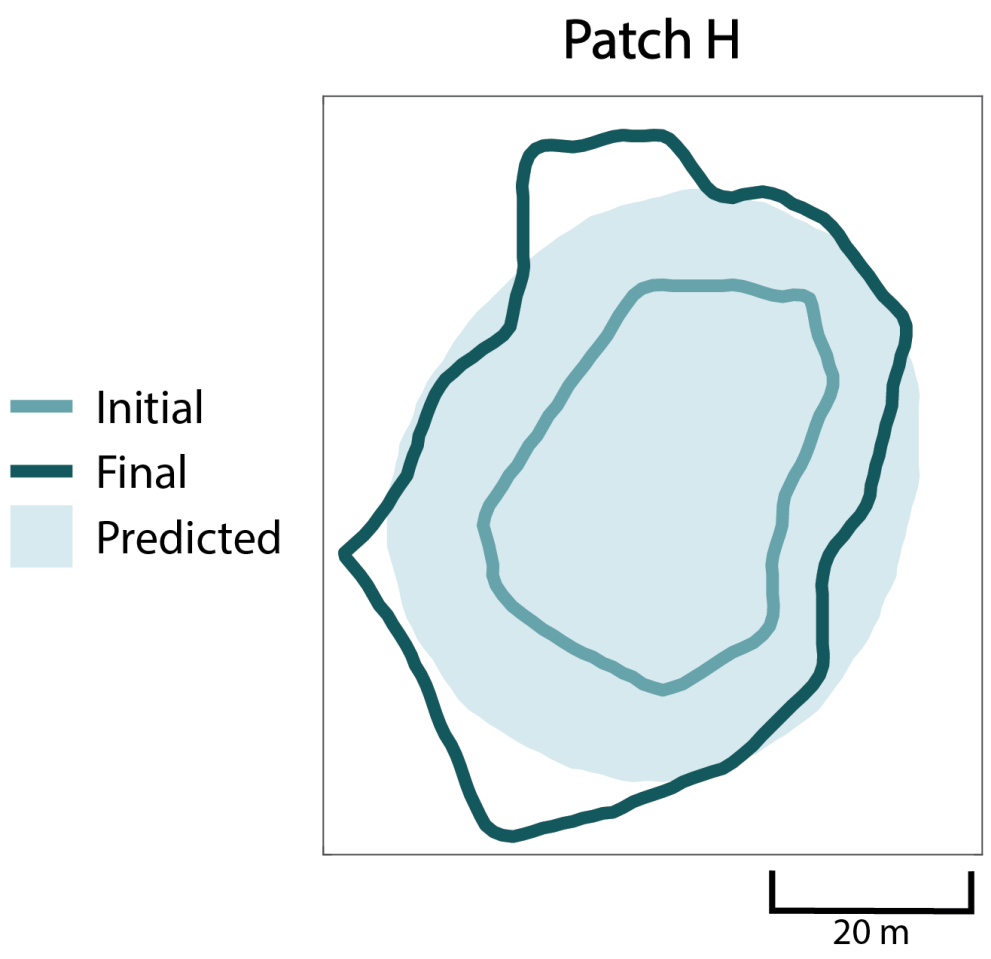

Figure E.8: Composite score of 0.818 


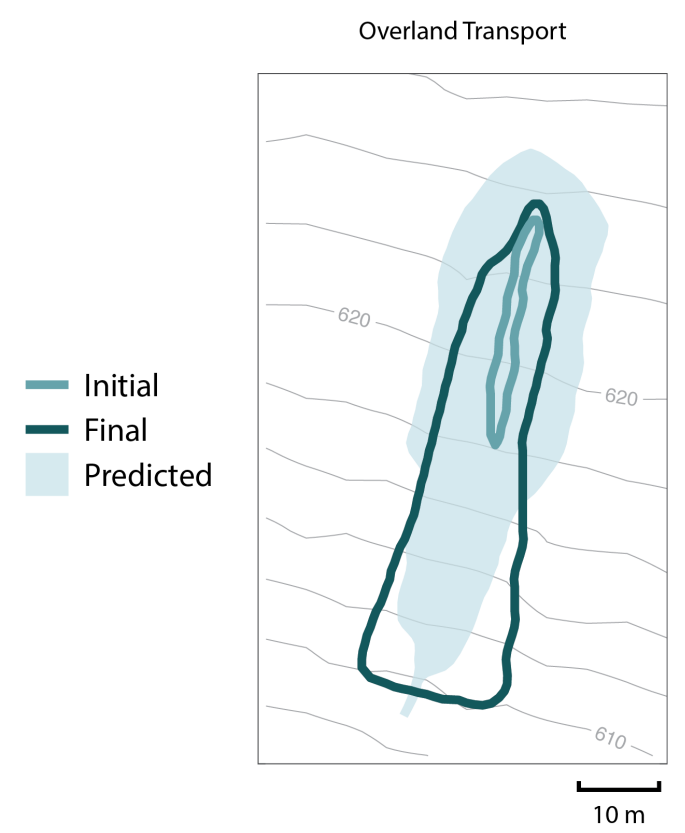

\section{Patch 1}

“Diffusion" Optimized

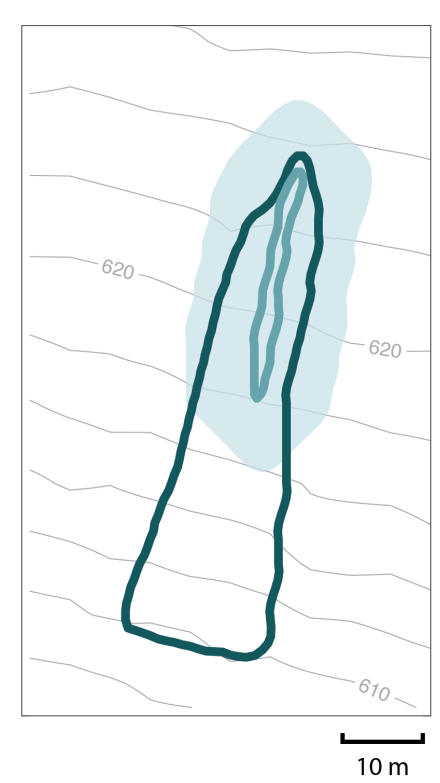

Overland Transport Turned Off

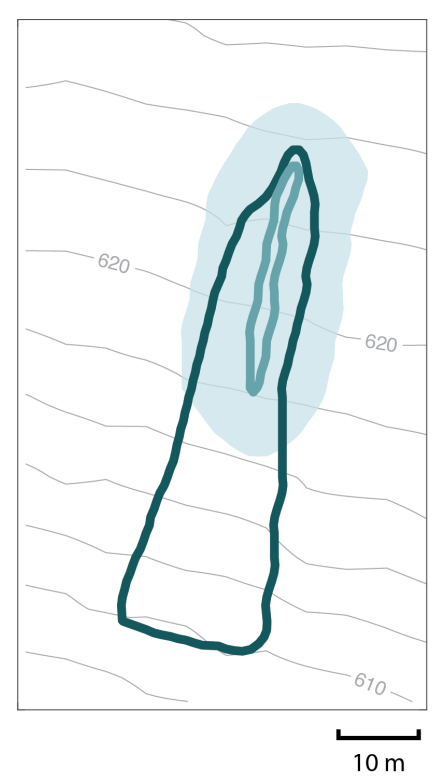

Figure F.1: Overland composite score of $0.866(\alpha=0.085)$, "diffusion" optimized composite score of 0.718 , overland transport off composite score of 0.714 
Patch 2

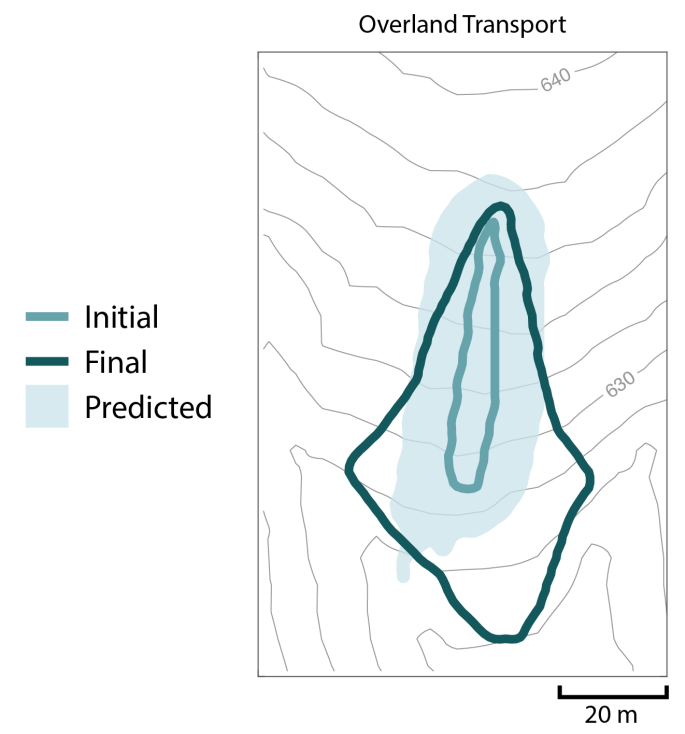

"Diffusion" Optimized

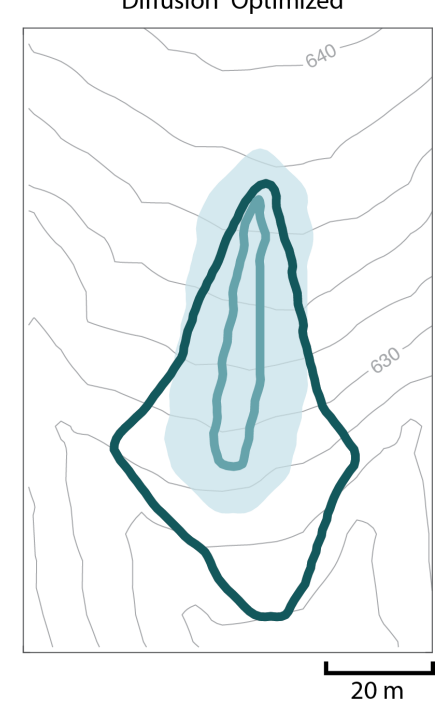

Overland Transport Turned Off

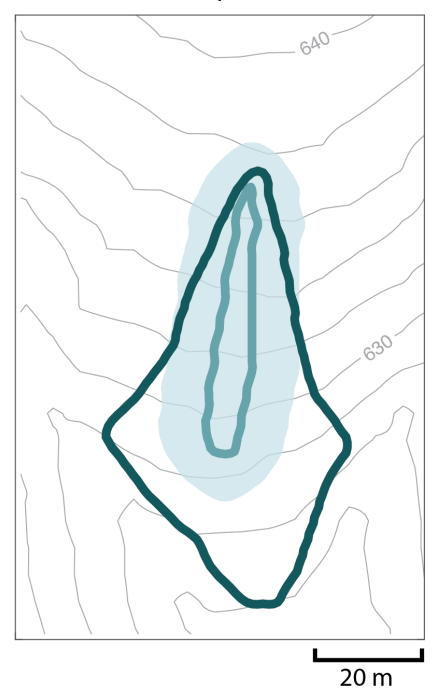

Figure F.2: Overland composite score of $0.833(\alpha=0.110)$, "diffusion" optimized composite score of 0.815 , overland transport off composite score of 0.811

Patch 3

"Diffusion" Optimized

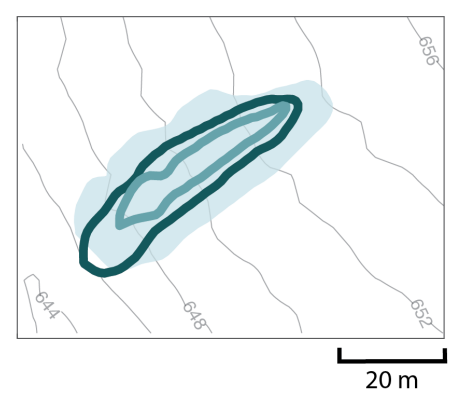

Overland Transport Turned Off

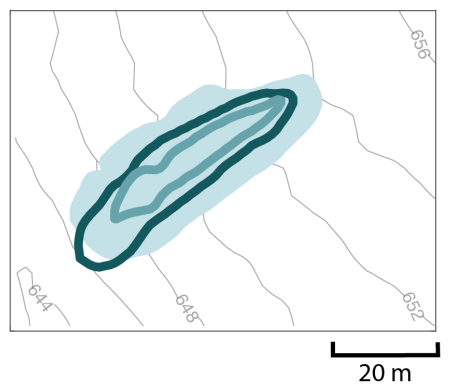

Figure F.3: Overland composite score of $0.834(\alpha=0.285)$, "diffusion" optimized composite score of 0.830 , overland transport off composite score of 0.835 


\section{Patch 4}

Overland Transport

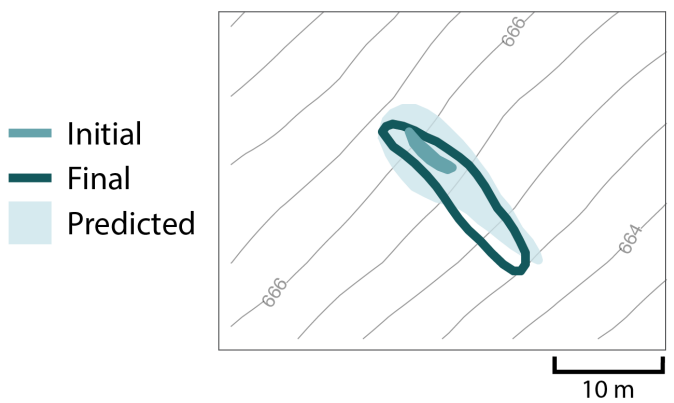

"Diffusion" Optimized

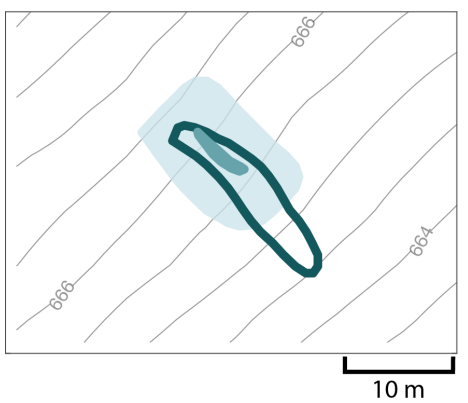

Overland Transport Turned Off

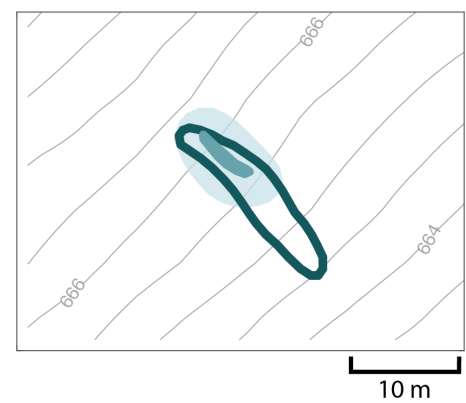

Figure F.4: Overland composite score of $0.860(\alpha=0.025)$, "diffusion" optimized composite score of 0.706, overland transport off composite score of 0.686

\section{Patch 5}

Overland Transport

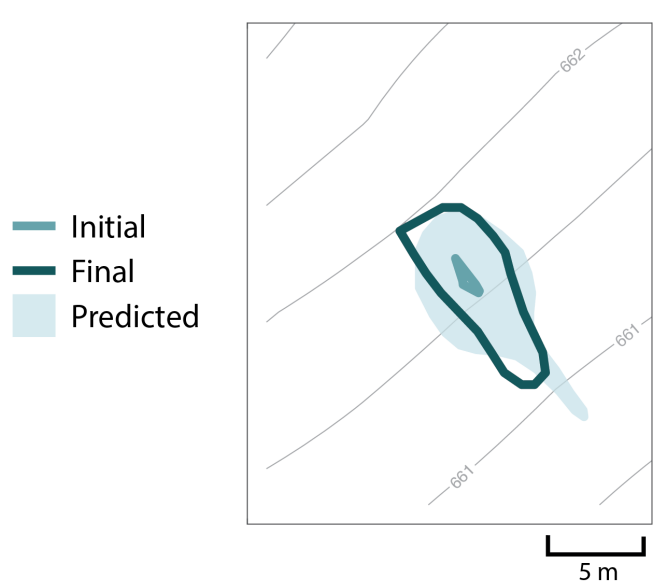

“Diffusion” Optimized

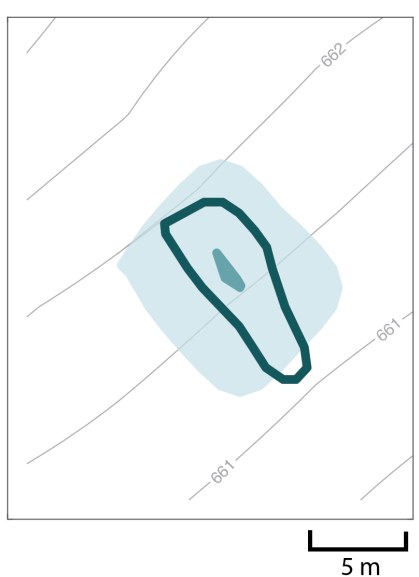

Overland Transport Turned Off

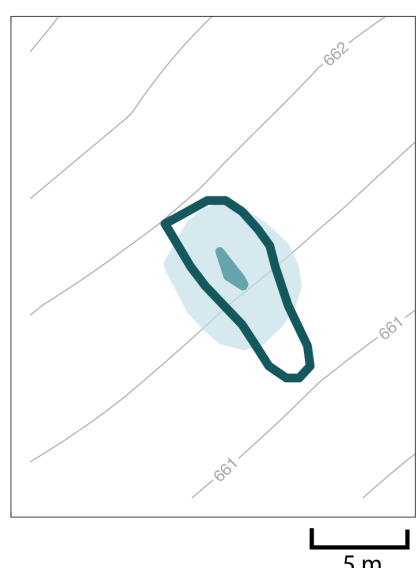

Figure F.5: Overland composite score of $0.885(\alpha=0.015)$, "diffusion" optimized composite score of 0.734, overland transport off composite score of 0.703 
Patch 6

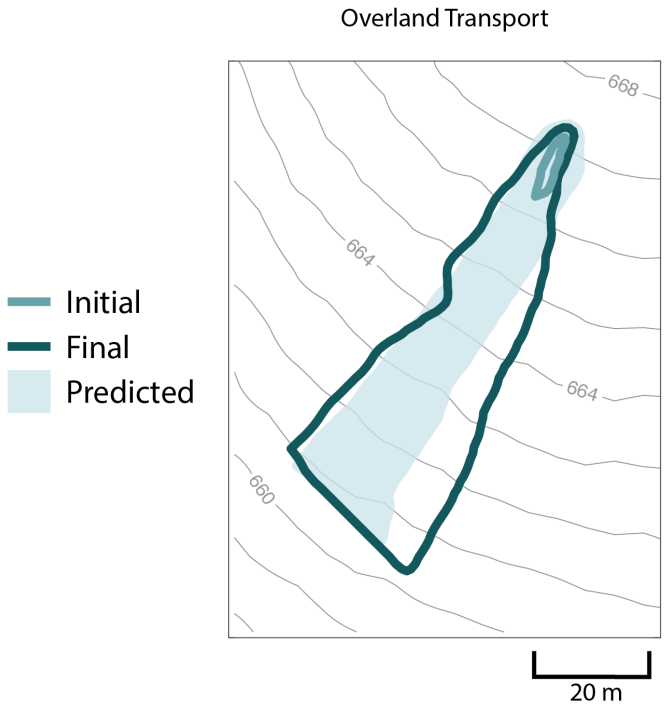

“Diffusion” Optimized

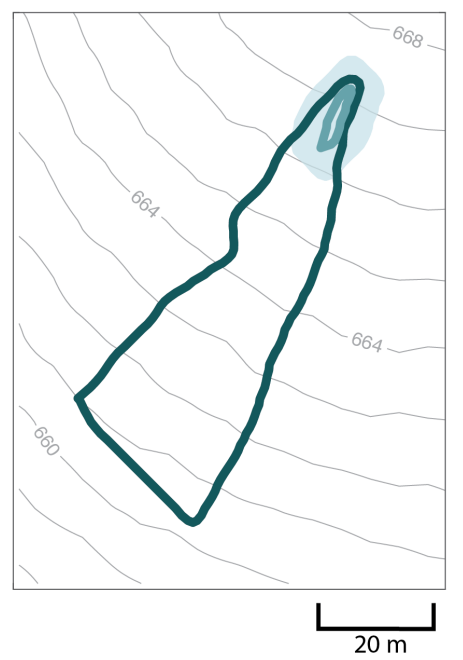

Overland Transport Turned Off

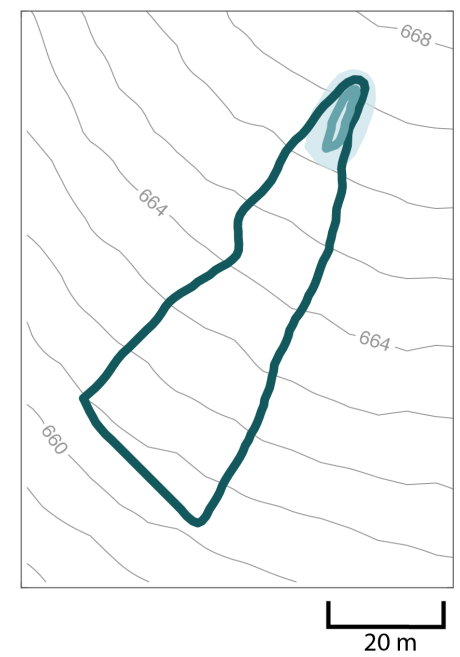

Figure F.6: Overland composite score of 0.859 ( $\alpha=0.007)$, "diffusion" optimized composite score of 0.546, overland transport off composite score of 0.533

Patch 7

“Diffusion” Optimized

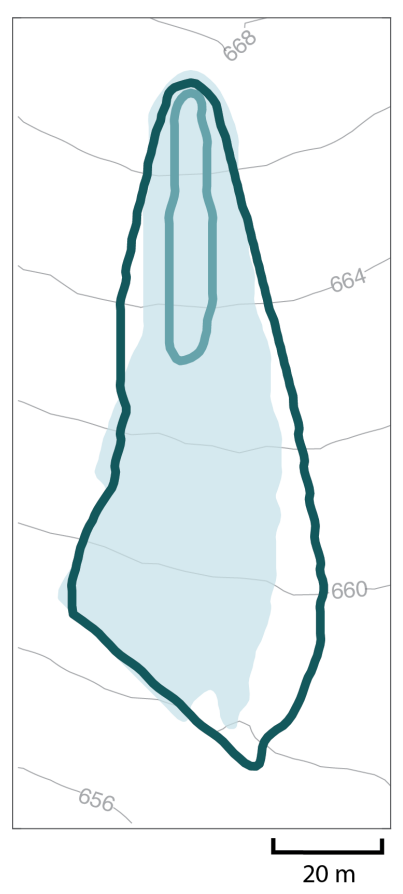

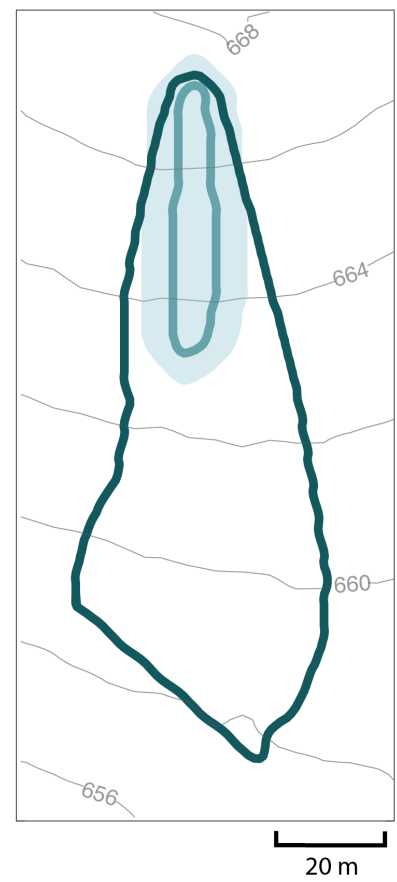

Overland Transport Turned Off

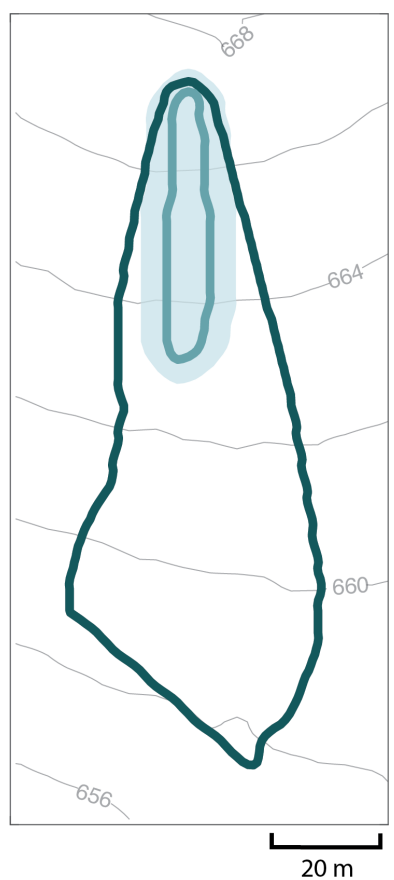

Figure F.7: Overland composite score of 0.913 ( $\alpha=0.0017)$, "diffusion" optimized composite score of 0.658 , overland transport off composite score of 0.646 


\section{G Hillslope Parameterization Results}

\begin{tabular}{l|l} 
Patch & $\alpha$ \\
\hline \hline 1 & 0.085 \\
2 & 0.110 \\
3 & 0.285 \\
4 & 0.025 \\
5 & 0.015 \\
6 & 0.007 \\
7 & 0.0017
\end{tabular}

Table G.1: Tuned $\alpha$ values specific to each patch at the Spanish site in the overland transport configuration.

\section{H Parameter Sensitivity Analysis}

Incomplete hydrological data at the study sites precluded detailed model calibration and validation, raising the possibility that parameter uncertainties could influence the hypothesis test. We therefore tested how sensitive the conclusion that pathogen transport in surface flow was required to generate the observed spread of disease by varying model parameters. Here we show the composite scores from the different model versions for Patch 7 after varying calibrated (Figure H.1) and non-calibrated model parameters (Figure H.2) over a range of $20 \%$. We also altered forcing data, including precipitation ( $P$ Figure H.2), in this case by varying event volume, not number of events.

Figures H.1 and H.2 show that the conclusion that surface transport is required to reproduce observed disease spread was robust to these changes in parameter values, with two exceptions: if the growth rate temperature dependence $(\Delta r)$ and precipitation $(P)$ were decreased by more than $20 \%$ then the model performance was comparable between the transport cases. The composite scores in all configurations were relatively low when $\Delta r$ was decreased by $20 \%$, suggesting that the comparable performance between the models reflects only the fact that both models perform poorly in this situation. When the precipitation was decreased by $20 \%$, no episodes overland flow occurred, and this results in the comparable performance of the models with/without such flow. However, as shown in Figure 5, satellite-based observations indicate saturation of soils does occur at this site in reality - thus this situation is not supported by remotely sensed hydrological observations. For all other parameter variations, the overland transport model configuration clearly outperformed other model configurations, suggesting that the conclusion that overland transport can be an important mechanism of pathogen spread is robust to parameter uncertainty expected given the lack of site-specific flow observations with which to calibrate the model. 


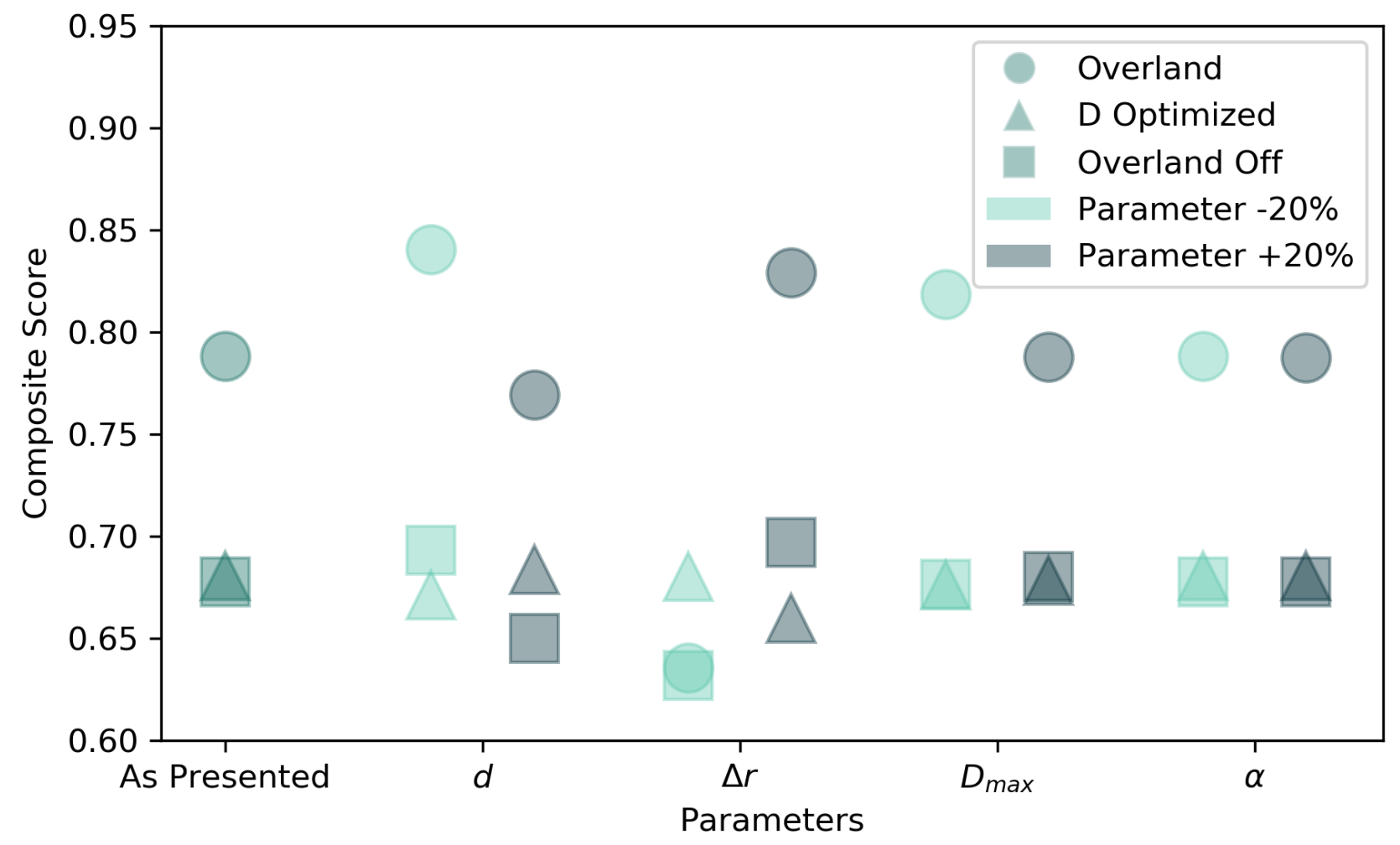

Figure H.1: Composite scores of different model set-ups (circle - including overland transport; triangle - "diffusion" only; square - overland transport turned off) shown when values of the tuned parameters are increased (darker) or decreased (lighter) by $20 \%$ as compared to the composite scores of the parameterization as presented in the main text. 


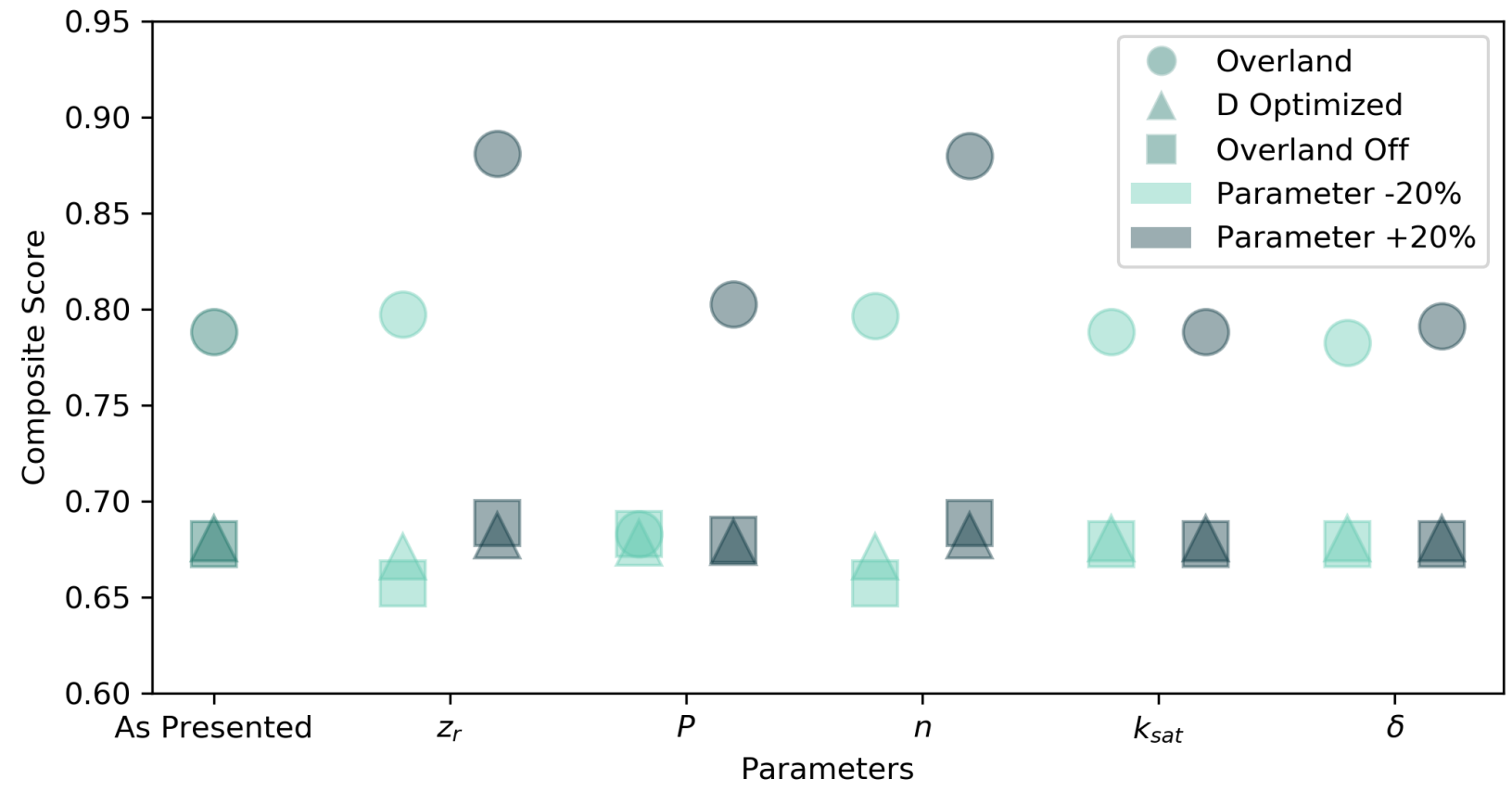

Figure H.2: Composite scores of different model set-ups (circle - including overland transport; triangle - "diffusion" only; square - overland transport turned off) shown when values of the non-tuned parameters are increased (darker) or decreased (lighter) by $20 \%$ as compared to the composite scores of the parameterization as presented in the main text. 